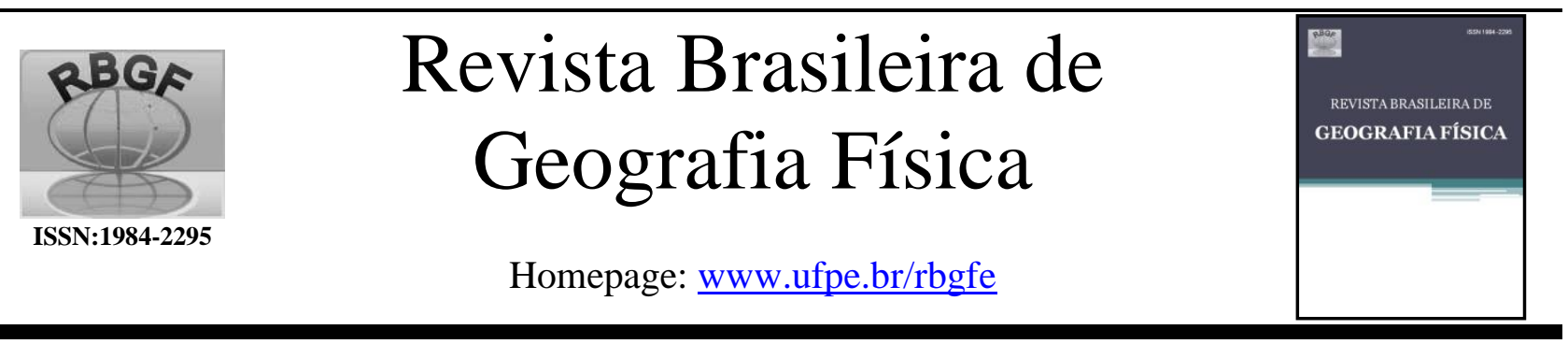

\title{
Habitação de interesse social: intencionalidades na realocação de moradias e reuso do solo no ambiente urbano ${ }^{1}$
}

\author{
${ }^{1}$ Manuela Maria Pereira do Nascimento e ${ }^{2}$ Cláudio Jorge Moura de Castilho
}

\begin{abstract}
${ }^{1}$ Doutoranda em Desenvolvimento e Meio Ambiente. Universidade Federal de Pernambuco - UFPE, Associação Plena em Rede - Doutorado em Desenvolvimento e Meio Ambiente - PRODEMA. E-Mail: manuelanascimento@ yahoo.com.br (autor correspondente). ${ }^{2}$ Professor Doutor do Departamento de Ciências Geográficas e do Programa de Pós-Graduação em Desenvolvimento e Meio Ambiente. E-mail: claudiocastilho44@gmail.com.
\end{abstract}

Artigo recebido em 02/02/2018 e aceito em 20/05/2018

\section{R E S U M O}

Esta pesquisa teve o propósito de avaliar conexões entre o acesso à moradia e suas formas de implementação como políticas públicas, em função de seu potencial e influência na melhoria da gestão territorial. Dessa forma, tendo como recorte espacial o Município do Recife - Estado de Pernambuco, Brasil, questionou-se: em que medida as ações referentes à habitação de interesse social têm contribuído para a redução das desigualdades sociais e o melhoramento no ambiente urbano? Por meio de pesquisa de dados primários e secundários, geoprocessamento e revisão da literatura, foram correlacionados os resultados das políticas habitacionais, a investigação de intencionalidades para a realocação de famílias e as ocupações e usos que foram atribuídos aos ambientes de saída. Os resultados indicam pouca efetividade das ações na redução do déficit habitacional e das desigualdades sociais no Recife. Além disso, suas motivações iniciais não foram, em sua maioria, atreladas às condições de vulnerabilidade vividas por expressiva parcela da população do Recife. Em relação aos reassentados, as ações não fomentam a melhoria da situação ocupacional e tem ocorrido um certo direcionamento das famílias para áreas onde estão as famílias de menor rendimento, reforçando assim a histórica fragmentação territorial. Apesar disso, os envolvidos reconheceram a melhoria na condição da moradia, sobretudo devido à alta precariedade encontrada nos seus lugares de vida anteriores. Os novos usos e ocupações dos ambientes de saída não demonstram aproveitamento do potencial da política para melhorias ambientais, prevalecendo os reusos vinculados à implantação do sistema viário.

Palavras-chave: Gestão territorial, provisão pública de habitações, instabilidade residencial, desigualdade, Recife.

\section{Public housing: intentionality in the dwellings reallocation and soil reuse in the urban environment}

\section{A B S T R A C T}

The main purpose of this research was to evaluate the connections between the access to housing and its forms of public policies implementation, due to its potential and influence in the improvement of territorial management. We focused on Recife's experience, city that is located in the state of Pernambuco, Brazil, based on the following questions: to what extent has public housing policy contributed to the reduction of social inequalities and to improvement in the urban environment? Through research of primary and secondary data, geoprocessing and review of the literature we correlated the results of the public housing policies, the investigation about the intentionality hidden behind the relocation of families as well as the occupations and uses related to the previous environments of affected families. The results indicate low effectiveness of actions in reducing housing deficit and social inequalities in Recife. Furthermore, in most of the cases, its initial motivations were not linked to the vulnerability conditions experienced by a significant portion of the population. Considering the resettled, the actions are not promoting improvement in terms of occupational situation, have displaced the families for lower-income ranges areas, which has resulted in territorial fragmentation. Nevertheless, families affected by public housing policy recognized the improvement with regard to the condition of the housing, especially when make comparisons with previous housing situation. The new uses and occupations of the previous environments don't demonstrate a use of the potential in this kind of policy for environmental improvements, whit prevailing reuses linked to the roads system building.

Keywords: Territorial management, public housing policy, residential instability, inequality, Recife.

\footnotetext{
${ }^{1}$ Artigo baseado em parte da tese de doutorado da primeira autora.
} 
Revista Brasileira de Geografia Física v11, n.02 (2018) 560-584.

\section{Introdução}

Soluções equitativas para lidar com a diversidade de demandas pelas porções do espaço urbano deveriam crescer tanto quanto os aumentos nas taxas de urbanização, periferização e seus consequentes agravos ambientais. Essa é uma afirmação fácil, porém de difícil aplicação. Em relação à demanda por moradia digna no Brasil, nota-se que a resolução de problemas complexos perpetuados ou emergentes nas formas de provisão ocorre a passos lentos, acentuando-se diante da insuficiente consideração das avaliações dos programas habitacionais pretéritos e desconsiderando-se o fato de que essas ações são as principais geradoras de elementos materiais em políticas públicas sociais (Monteiro e Veras, 2017).

A desproporção no fator "deveria ser/como ocorre" é notória perante a disponibilidade de materiais técnico-acadêmicos associados à busca de tais soluções, que tratam tanto de fatores para um melhor planejamento do setor habitacional, como de sua inserção em formas mais equilibradas de gestão das cidades. Mais especificamente, têmse dados geoespaciais e socioeconômicos abertos; análises críticas quantitativas e/ou qualitativas em estudos acadêmicos ou relatórios técnicos, tais como Rolnik et al. (2011), Moreira e Ribeiro (2016) ou Proni e Faustino (2016); livros, que como em Cardoso et al. $(2013,2017)$, retratam a continuidade das deficiências na gestão financeira, social e territorial de políticas públicas, além de comprovar as especificidades do problema nas diferentes regiões brasileiras; e também artigos como o de Lima et al. (2016), que abordam a questão da participação popular, dentre outros materiais relevantes na crescente produção sobre o tema (Rodrigues e Moreira, 2017).

Segundo Geneletti et al. (2017), ainda existem muitas limitações em relação à pesquisa sobre teorias e métodos de planejamento sustentável para as periferias urbanas, destacando que é rara a discussão sobre a transferibilidade de métodos propostos, assim como que há oportunidades inexploradas para a melhoria de práticas de planejamento. Entretanto, mesmo levando-se isso em conta, apenas com um breve levantamento em busca de alternativas para satisfação de demandas e problemas de natureza territorial, pode-se inferir que o cerne das "questões irresolvíveis" das cidades, não está na falta de conexão entre os materiais sobre o tema, mas na efetiva prática desse conteúdo para a gestão.

Além disso, corriqueiramente, parece impossível eliminar os vieses da influência do capital empresarial na gestão pública do território, influência essa, que atua em oposição às realidades cultural, social e material que formam conjuntamente o habitat (Otálvaro-Sierra, 2013). Ao mesmo tempo, aliada à resistência quanto a projetos urbanísticos "não convencionais", verifica-se uma naturalização dos efeitos adversos da implementação de ações por parte do poder público. Efeitos que acabam se confundindo em meio aos demais problemas da cidade, traduzindose no que Bueno (2008) define como um ambiente construído que, historicamente, apresenta-se sempre em um estado de urbanização incompleta.

Nesse estado, cresce a "periferia", que para Geneletti et al. (2017), abarcando a complexidade do fenômeno, está relacionada à existência de algumas características que se referem a disparidades geográficas, econômicas, políticas e sociais, que trazem como consequência a dependência, desconexão (em relação ao acesso à educação ou ao mercado de trabalho), pobreza e emigração. Tais efeitos expressariam uma condição de "ser periférico" em qualquer situação espacial ao invés da noção de subúrbios ou áreas periurbanas, por exemplo.

A persistência dessas premissas envolve qualquer área de ação no território, seja a implantação de uma grande obra viária, a instalação de um parque, um posto de saúde ou a autorização para a construção de empreendimentos privados de qualquer finalidade. Tais efeitos acabam tornando-se questões "de fundo" diante dos resultados quantitativos, das materialidades consumadas, e tal como afirma Höfling (2001), findam abstraindo-se da integralidade que deve ser inerente às políticas públicas sociais.

De tal modo, na gestão do ambiente urbano, os fatos e problemas - setorizados, fragmentados, burocratizados em secretarias municipais ou estaduais, fundações e autarquias mesmo reconhecendo-se os esforços de integração de políticas públicas entre si, com organizações da sociedade civil e parcerias público-privadas positivas nos últimos anos, imbricam-se no curso da vida, do trabalho e no movimento das pessoas. Então o social não se entende com o técnico; a infraestrutura ou habitação trabalham, mas não há verba na saúde, saneamento ou educação para complementar os projetos e manter áreas "revitalizadas" (Monteiro, 2015), gerando mais problemas onde já havia sido aplicada alguma solução.

Em outras palavras, aplica-se uma solução com o fim de realizar uma determinada intervenção comumente adjetivada com o status de interesse público, social ou de recuperação/melhoria ambiental (nesse estudo, está em questão a construção de conjuntos habitacionais para realocar famílias e o reuso de áreas de remoção); a 


\section{Revista Brasileira de Geografia Física v11, n.02 (2018) 560-584.}

tal solução traz benefícios, mas também efeitos negativos que carecem de um balanceamento relativo à sua influência na dinâmica socioterritorial, no estado do ambiente urbano e na vida das pessoas envolvidas.

Em se tratando do processo recente de provisão de moradias subsidiada pelo Estado, as pesquisas demonstram a persistência de problemas em meio aos avanços quantitativos no que se refere à acessibilidade à habitação (Cardoso e Aragão, 2013). Alguns exemplos dessa persistência traduzem-se no crescimento dos assentamentos precários e da ocorrência de ocupações urbanas como solução de acesso à moradia para os mais pobres, um dissenso em relação aos avanços nas formas institucionalizadas da provisão de "interesse social" (Nascimento, 2016). O que, aliás, não poderia deixar de acontecer em função da permanência no tempo-espaço dos princípios fundamentais inerentes à lógica do processo de produção social do espaço nas cidades brasileiras, os quais, se não forem atingidos, nunca se terá a mudança efetiva que se almeja.

Moreira e Ribeiro (2016) avaliam, a partir de uma visão abrangente das políticas habitacionais brasileiras e dos seus efeitos, que ocorre a reprodução contraditória de um padrão de segregação socioterritorial, precariedade urbana e ambiental, agravado pela permanência da desvinculação entre as políticas de provisão e de regularização fundiária. Ao longo da história, tais efeitos são frutos da permanência da influência estratégias de agentes do sistema capitalista na provisão habitacional, uma vez que ela está frequentemente articulada a ações que visam ao crescimento econômico em detrimento de seus princípios norteadores (Oliveira et al., 2017) vinculados à lógica acima ressaltada.

Dessa forma, distante das evidências dos dados, pesquisas ou relatórios, as mudanças no plano político e administrativo se esvaem no mau direcionamento e na falta de acompanhamento dos projetos, seja aqueles que envolvem a cessão de altos subsídios governamentais para aquisição da casa própria (como o Programa Minha Casa Minha Vida-PMCMV) ou daqueles referentes ao reassentamento voluntário e involuntário de famílias (como nas Políticas de Habitação de Interesse Social-PHIS e suas ramificações no Programa de Aceleração de Crescimento-PAC, realizadas por meio do uso do Fundo Nacional de Habitação de Interesse Social - FNHIS).

Para Balbin et al. (2015), o PMCMV ascendeu de um programa à efetiva política habitacional brasileira, esvaziando ações em que havia outras possibilidades de provisão habitacional, tornando-se uma solução massificada de habitação de interesse social (HIS), que, ao final, não se trata de HIS, pois atua contrariamente às diversidades urbanas, organizacionais e familiares dos envolvidos.

No mesmo caminho dessa maior abrangência, o PMCMV também tem sido alvo da maioria dos estudos sobre a provisão habitacional recente no Brasil (Rodrigues e Moreira, 2017). Assim, indo na direção de outras frentes, esta pesquisa se concentrou nos empreendimentos associados à habitação de interesse social "mais propriamente dita".

Quanto a esses "guarda-chuvas" da provisão habitacional no país, Krause et al. (2013) reconhecem detalhadamente as deficiências e os desafios dos referidos programas iniciados na década passada, suas inter-relações entre si e com o PAC, mas também destacam o seu papel na ampliação do atendimento a famílias que se situam em faixas de renda mais baixas, que sofriam com restrições ainda maiores no que concerne ao acesso digno à casa própria antes da primeira década dos anos 2000.

De acordo com Zhang (2016), a acessibilidade à habitação, a despeito dos avanços quantitativos verificados em escala mundial, ainda faz parte do elenco principal de problemas e desafios gerados pelo rápido crescimento urbano, em contextos de realidades socialmente problemáticas. Em sua pesquisa, o autor analisou cidades em países desenvolvidos e "em desenvolvimento", colocando que a demanda por habitações faz parte de um conjunto que envolve a expansão e pobreza urbana, altas taxas de desemprego e o elevado custo de vida nas cidades, a falta de investimento em infraestruturas, a baixa capacidade financeira e de governança, o aumento da desigualdade, da criminalidade e a degradação ambiental.

Com o intuito buscar elementos empíricos que contribuam para evidenciar tais conexões no acesso à moradia, suas formas de implantação tais como políticas públicas e possibilidades de melhoria na gestão socioterritorial, estabeleceu-se a questão que norteou esta pesquisa: em que medida as ações em habitação de interesse social têm contribuído para a redução das desigualdades sociais e ao melhoramento do ambiente urbano?

A pesquisa baseou-se, de forma geral, na conexão entre os resultados das políticas habitacionais, na investigação das intencionalidades para a realocação de famílias no espaço urbano e nas ocupações e usos que foram atribuídos aos "ambientes de saída", ou seja, aqueles em que as famílias habitavam anteriormente, ocorrendo na continuidade da realização de um levantamento dos conjuntos 
Revista Brasileira de Geografia Física v11, n.02 (2018) 560-584.

habitacionais construídos em PHIS, entre 2001 e 2016, no município do Recife (Nascimento e Bautista, 2016).

$\mathrm{Na}$ sequência, encontram-se os procedimentos metodológicos adotados na pesquisa, seguidos dos resultados e discussão que foram divididos em duas seções que tratam: (a) da discussão das relações entre o déficit habitacional, a instabilidade residencial e a implantação de PHIS na área de estudo e (b) das ocupações e usos nos locais de remoção e verificação do contexto socioterritorial de reinserção das habitações, a partir da distribuição de rendimentos médios mensais no município e localização das intervenções, bem como da percepção das mudanças nas condições de ocupação da população realocada, seu desejo de permanência nos ambientes de saída e satisfação quanto à transferência para conjunto habitacional.

\section{Material e métodos}

\section{Delimitação da área de estudo}

O recorte espacial do estudo compreende o Município do Recife, estado federado de Pernambuco, fazendo-se algumas ponderações, uma vez que o município acha-se localizado em contexto temporo-espacial muito mais abrangente em relação ao processo estudado, que não se poderia isolar do todo. $\mathrm{O}$ recorte teve duas dimensões (Figura 1): o conjunto do território municipal, para análise dos processos de remoção de moradias em intervenções do poder público, que envolvessem a construção de habitações de interesse social; fragmentos do território, considerando os locais de situação de conjuntos habitacionais inseridos nesses processos entre 2001 e 2016 e os lugares de origem dos reassentados, denominados de ambientes de saída. Utilizou-se o termo "de saída" em relação à saída da residência, uma vez que mesmo sem um grande deslocamento espacial, as famílias saíram de sua condição de moradia.

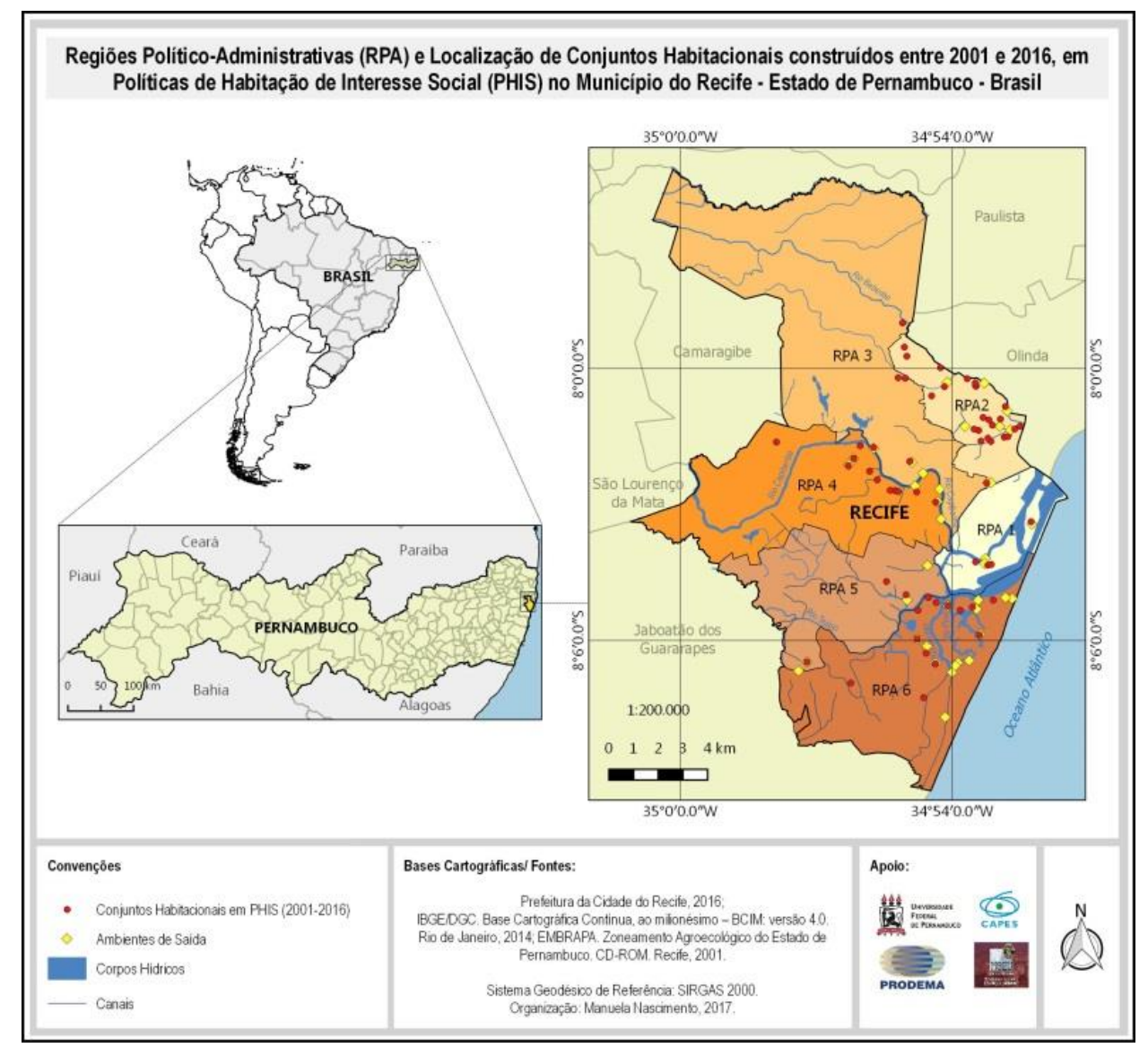

Figura 1. Localização geral da área de estudo.

Considerando-se a análise cartográfica, informações documentais e obtidas junto a órgãos públicos, foram identificados 60 conjuntos habitacionais e 37 ambientes de saída. A quantidade destes ambientes é menor, uma vez que em parte dos conjuntos levantados foram alojadas pessoas desabrigadas ou em moradias em situação de risco dispersas pela cidade e de difícil 
Revista Brasileira de Geografia Física v11, n.02 (2018) 560-584.

mapeamento, bem como porque alguns ambientes de saída tiveram seus moradores distribuídos em vários conjuntos.

\section{Procedimentos metodológicos}

A partir da verificação empírica de situações em campo e análise da literatura pertinente, observou-se a necessidade de fazer a análise do processo a partir de diversas fontes de dados, sendo realizados os procedimentos que serão detalhados por tópicos a seguir. O projeto foi submetido ao Comitê de Ética em Pesquisa-CEP, instância colegiada da Universidade Federal de Pernambuco, sendo aprovado por meio do Parecer Consubstanciado número 1.906.122.

(I) Levantamento de dados secundários e informações - Os dados secundários, assim como outras informações relevantes para a pesquisa, foram pesquisados junto às seguintes instituições: Instituto Brasileiro de Geografia e Estatística (IBGE); Portais do Governo Federal (Transparência, Dados Abertos e Ministério das Cidades); Portal da Caixa Econômica Federal; Fundação João Pinheiro (FJP), Secretarias de Estado e Municipais de Planejamento, Meio Ambiente e Habitação, Fundações Estatuais e Municipais de Pesquisa.

O levantamento mais específico dos conjuntos habitacionais em PHIS foi realizado na Secretaria de Habitação da Prefeitura do Recife, na Empresa de Urbanização do Recife (URB), na Autarquia de Saneamento do Recife (Sanear) e nas Secretarias de Habitação (SecHab), de Planejamento e das Cidades do Governo do Estado de Pernambuco. Nesse ponto deve-se ressaltar que $\mathrm{o}$ apoio da análise cartográfica e pesquisa em campo foram fundamentais, devido à segmentação e lacunas das informações fornecidas pelos órgãos públicos. Apesar do esforço para contemplar o universo dos empreendimentos, viu-se que essa era uma tarefa difícil de ser checada em sua totalidade. Entretanto, com as checagens também em materiais produzidos por meio de pesquisas acadêmicas, verificou-se que o levantamento teve uma boa abrangência, isso desconsiderando ações em lugares onde possam ter sido construídas habitações em pequenos agrupamentos, resultado de projetos de HIS realizados apenas com recursos do município ou estado.

A pesquisa bibliográfica e documental foi realizada nos locais referentes à pesquisa de dados secundários bem como nas bibliotecas $\mathrm{e}$ departamentos da Universidade Federal de Pernambuco, além de portais na Internet, por meio do Banco de Teses e Dissertações e Periódicos da Capes, da Biblioteca Eletrônica Scielo e Science
Direct, ou diretamente em sites de revistas científicas, jornais digitais e anais eletrônicos.

(II) Geoprocessamento - Realizou-se uma abordagem espacialmente explícita (Moran, 2011), levando-se em conta que,

A análise fundada na espacialidade possui a singular capacidade de dar visibilidade única, em termos metodológicos, à realidade social. Isto porque integra setores e atividades, conjuga expressões políticas e socioculturais; explicita conflitos em áreas centrais e periféricas; aponta zonas de insegurança social e de risco ambiental [...]. (Matos, 2008, p. 386).

Estes procedimentos tiveram o suporte de tecnologias livres, visando à democratização dos procedimentos e a dirimir a dificuldade quanto à obtenção de licenças de uso; sendo assim, foi priorizado o uso do Sistema de Informação Geográfica livre e aberto QGis (versão 2.14.11).

As bases cartográficas utilizadas foram ortofotocartas digitais e fotografias aéreas referentes aos anos de 2002, 2005, 2007 e 2013/2014, além de uma base vetorial que contempla a divisão político-administrativa, Zonas Especiais de Interesse Social, logradouros e drenagem do Recife, referente ao ano de 2015, do Zoneamento Urbano determinado pelo Plano Diretor do Recife de 2008, dos levantamentos de áreas pobres referentes aos anos de 1978, 1988 e 1998/2001 e cadastramento de Comunidades de Interesse Social (CIS), realizado pela Prefeitura do Recife no ano de 2014. Estes materiais foram cedidos gratuitamente pela Prefeitura do Recife e pela Agência Estadual de Planejamento e Pesquisa de Pernambuco-CONDEPE/FIDEM.

Para a finalização da produção cartográfica, foram observadas imagens de satélite mais atualizadas (anos de 2016 e 2017), obtidas por meio do aplicativo Google Earth PRO, as quais também serviram de base para a localização dos conjuntos habitacionais. Como base e fonte de informação auxiliar na produção de mapas, também foi utilizada a base cartográfica do IBGE.

$\mathrm{Na}$ observação dos fragmentos territoriais, as ortofotocartas foram sobrepostas às bases vetoriais e levantamento dos conjuntos habitacionais recentes. As sobreposições possibilitaram a visualização dos padrões de transformações espaço-temporais e foram estabelecidos indicadores para observação das trajetórias de realocação no ambiente urbano para o município como um todo. Essa análise comparativa por sobreposição do material cartográfico disponível, também serviu de base para a demarcação dos ambientes de saída e áreas de reocupação nas proximidades de onde as 


\section{Revista Brasileira de Geografia Física v11, n.02 (2018) 560-584.}

famílias foram retiradas. Nessas demarcações, utilizou-se a imagem mais recente na qual ainda apareciam as habitações, de acordo com cada caso.

Foram elaborados dois cartogramas para a correlação de dois indicadores socioeconômicos básicos (densidade demográfica e rendimento médio mensal domiciliar), com a localização dos conjuntos habitacionais e locais de saída das famílias. Para isso foram utilizadas a malha de setores censitários e tabelas de dados do agregado de setores censitários do IBGE (Quadro 1).

Quadro 1. Registro de variáveis do Censo 2010 utilizadas para composição de cartogramas.

\begin{tabular}{|c|c|c|c|}
\hline \multirow[b]{2}{*}{ Indicador } & \multicolumn{3}{|c|}{2010} \\
\hline & Planilha & $\begin{array}{c}\text { Código da } \\
\text { Variável } \\
\end{array}$ & Descrição \\
\hline \multirow{2}{*}{$\begin{array}{l}\text { Média de moradores em DPP } \\
\text { por setor censitário (MMD) }\end{array}$} & $\begin{array}{l}\text { Domicílio, características } \\
\text { gerais (Domicilio01_UF.xls) }\end{array}$ & V002 & Total de DPP ${ }^{1}$ \\
\hline & $\begin{array}{l}\text { Domicílio, moradores } \\
\text { (Domicilio02_UF.xls) }\end{array}$ & V002 & Total de Moradores em DPP \\
\hline \multirow{2}{*}{$\begin{array}{l}\text { Rendimento nominal mensal } \\
\text { médio dos domicílios } \\
\text { particulares permanentes por } \\
\text { setor censitário (RMD) }\end{array}$} & $\begin{array}{c}\text { Domicílio, características } \\
\text { gerais (Domicilio01_UF.xls) }\end{array}$ & V002 & Total de DPP \\
\hline & $\begin{array}{l}\text { Renda dos Domicílios } \\
\text { (DomicílioRenda_UF.xls) }\end{array}$ & V003 & $\begin{array}{l}\text { Total do rendimento nominal } \\
\text { mensal dos domicílios } \\
\text { particulares permanentes }\end{array}$ \\
\hline
\end{tabular}

${ }^{1}$ DPP $=$ Domicílios Particulares Permanentes. Fonte: IBGE (2011).

(III) Observação direta e pesquisa de dados primários - A pesquisa de dados primários por meio de entrevistas teve como meta a avaliação do processo de realocação sob o ponto de vista das populações humanas residentes nos conjuntos habitacionais. Foi observado de que modo o afastamento de seu local de moradia anterior, interferiu em suas práticas sociais e relações com o ambiente. Nesse sentido, foram realizadas entrevistas semiestruturadas com questões abertas e fechadas, cuja amostra das populações foi gerada de acordo com a tipologia (morador do conjunto habitacional e lideranças comunitárias), seguindo os critérios do plano amostral explicitado mais adiante.

$\mathrm{O}$ roteiro de entrevistas, que gerou $\mathrm{o}$ instrumento de coleta, foi elaborado a fim de atender a meta acima mencionada, sendo dividido em quatro temas e tendo como referência o trabalho de sistematização elaborado por Prado (2012), em associação com os conteúdos teóricometodológicos discutidos quanto a práticas de afastamento e aproximação nas relações sociedade e natureza (Nascimento, 2017). Devido à amplitude das informações obtidas nessas entrevistas, nesse artigo serão discutidas apenas as questões que têm como foco a problemática exposta na introdução.

O plano amostral adotado correspondeu a uma amostragem por conglomerados (Bolfarine e Bussab, 2005) em dois estágios, pelo qual, no primeiro estágio, os conglomerados foram selecionados de acordo com um procedimento de amostragem sistemática, enquanto que, no segundo, selecionaram-se os domicílios, dentro dos conglomerados sorteados, por amostragem aleatória simples sem reposição. A seguir será explicado o primeiro estágio, pela aplicação do procedimento de amostragem sistemática.

Considerando-se a distribuição dos conjuntos habitacionais mapeada na fase de geoprocessamento e tendo como referência o período entre os anos de 2001 e 2016, em que foram levantados 60 conjuntos habitacionais, foi definido o universo para a análise, equivalente a 6.006 domicílios já entregues, distribuídos em 37 conjuntos concluídos. Foram excluídos do universo os conjuntos em obras ou paralisados ou que não foram destinados exclusivamente à realocação de famílias, uma vez que foram construídos para suprir a demanda de famílias desabrigadas por ocorrência de chuvas, deslizamentos ou que residiam em áreas de risco. Estes conjuntos foram excluídos na medida em que se levou em conta que, neles, não houve o reassentamento involuntário de famílias.

Selecionou-se um condomínio aleatoriamente, e em sequência, os demais condomínios participantes da amostra foram selecionados em intervalos de três em três, considerando-se uma ordem estabelecida em função da distribuição dos conjuntos partindo do norte para o sul do município do Recife, percorrendo todo o território municipal. O conjunto 14 foi o primeiro selecionado aleatoriamente, seguindo-se a definição dos demais. Assim, foram selecionados 13 conglomerados.

O tamanho da amostra foi calculado supondo-se que o objetivo é estimar a proporção com a qual uma determinada característica ocorre na população formada pelas unidades habitacionais 
que compõem os 37 condomínios em causa. Assumindo-se que tal proporção é estimada a partir de uma amostra aleatória simples sem reposição (Bolfarine e Bussab, 2005), o tamanho amostral foi dado por

$$
n=\frac{N}{P(1-P)(N-1) \frac{B^{2}}{z_{\alpha}^{2}}+1}
$$

Onde, $N$ refere-se à quantidade de domicílios, $P$ à proporção, $B$ ao erro amostral e $z_{\alpha}$ ao quantil de ordem $1-\frac{\alpha}{2}$ da distribuição normal padrão. Para utilizar esta fórmula, é necessário especificar um valor para $P$. Uma maneira de produzir um valor conservativo para o tamanho amostral é utilizar o fato de que $P(1-P) \leq 1 / 4$. Neste caso,

$$
n=\frac{N}{4(N-1) \frac{B^{2}}{z_{\alpha}^{2}}+1} .
$$

Nesta pesquisa, considerou-se um erro amostral de $B=10 \%$ com $1-\alpha=90 \%$ de confiança. Portanto, o tamanho amostral ficou dado por

$$
n=\frac{6006}{4(6006-1) \frac{0,1^{2}}{z_{0,90}^{2}}+1} \approx 66,8963 \approx 67 .
$$

Este resultado indicou a seleção de 67 unidades habitacionais, onde, em cada qual, seria aplicada uma entrevista. Estas 67 unidades foram distribuídas nos 13 conglomerados observando-se a proporção que cada conglomerado ocupava dentro da população total e domicílios. Isto é, para cada conjunto habitacional foi selecionada uma quantidade de domicílios equivalente à proporção da população que cada um representava, aplicandose a fórmula

$$
\frac{U H}{P T}
$$

Onde, $U H$ refere-se ao número de unidades habitacionais de um determinado conjunto habitacional e $P T$, trata-se do total de unidades habitacionais dentre os 13 conjuntos selecionados.

$\mathrm{O}$ resultado deste cálculo encontra-se na coluna TAC da tabela abaixo (Tabela 1). Os valores obtidos foram arredondados para cima (TAA) e, por fim, estabeleceu-se um tamanho amostral mínimo de três unidades habitacionais por conjunto. $\mathrm{O}$ resultado da aplicação deste procedimento encontra-se na coluna TAE (Tamanho Amostral Efetivo), sendo esses os tamanhos amostrais que foram utilizados por conjunto. Assim, o tamanho da amostra de unidades habitacionais passou a ser de 78. Em cada conjunto habitacional, foi prevista a entrevista de uma liderança/representante dos moradores, caso fosse identificada pelos mesmos, resultando na aplicação de mais 13 entrevistas. Portanto, o número total de entrevistas previstas chegou a 91. Em seis conjuntos habitacionais não houve indicação de liderança, então as entrevistas com lideranças foram reduzidas de treze para sete, resultando em um total de 85 entrevistas realizadas.

Foram entrevistadas 45 pessoas que se identificaram com o gênero feminino e 40, com o masculino. A quantidade de pessoas entrevistadas por faixa etária foi a seguinte: de 18 a 20 (4), de 21 a 30 (18), de 31 a 40 (20), de 41 a 50 (15), de 51 a 60 (15), de 61 a 70 (7), de 71 a 80 (5), mais de 80 anos (1), resultando em uma idade média de 43 anos. Em média, os entrevistados residem há seis

\begin{tabular}{|c|c|c|c|c|c|}
\hline Código & Conjunto Habitacional $\left({ }^{1}\right.$ RAS) & ${ }^{2} \mathbf{U H}$ & ${ }^{3}$ TAC & ${ }^{4}$ TAA & ${ }^{5}$ TAE \\
\hline 4 & Conjunto Minerva (R4) & 98 & 2,6822 & 3 & 3 \\
\hline 10 & Conjunto Residencial Solano Trindade (R-17) & 35 & 0,9579 & 1 & 3 \\
\hline 14 & Conjunto Habitacional Felicidade (H05) & 40 & 1,0948 & 2 & 3 \\
\hline
\end{tabular}
anos nos conjuntos habitacionais, mas esses períodos variam entre 11 meses e 15 anos.

Tabela 1. Detalhamento dos quantitativos referentes ao planejamento amostral. 
Revista Brasileira de Geografia Física v11, n.02 (2018) 560-584.

\begin{tabular}{|c|c|c|c|c|c|}
\hline 18 & Conjunto Habitacional Palha do Arroz (H-01) & 227 & 6,2128 & 7 & 7 \\
\hline 21 & Conjunto Habitacional Santo Antônio (H19) & 128 & 3,5033 & 4 & 4 \\
\hline 25 & Conjunto Habitacional Beira Rio (H03) & 320 & 8,7582 & 9 & 9 \\
\hline 33 & Conjunto Habitacional Abençoada por Deus & 428 & 11,7141 & 12 & 12 \\
\hline 38 & Conjunto Habitacional Bueirão & 50 & 1,3685 & 2 & 3 \\
\hline 44 & Conjunto Travessa do Gusmão & 160 & 4,3791 & 5 & 5 \\
\hline 48 & Conjunto Habitacional Brasília Teimosa & 240 & 6,5686 & 7 & 7 \\
\hline 52 & Conjunto Habitacional Via Mangue II & 320 & 8,7582 & 9 & 9 \\
\hline 56 & Conjunto Residencial São Francisco de Assis & 50 & 1,3685 & 2 & 3 \\
\hline 60 & Conjunto Habitacional Via Mangue III & 352 & 9,6340 & 10 & 10 \\
\hline & Total de unidades habitacionais ( $\left.{ }^{6} \mathbf{P T}\right)$ & 2448 & \multirow{2}{*}{\multicolumn{2}{|c|}{$\begin{array}{l}\text { Entrevistas com moradores } \\
\text { Entrevistas com lideranças }\end{array}$}} & 78 \\
\hline & & & & & 13 \\
\hline & & & \multicolumn{2}{|c|}{ Total de entrevistas (amostra) } & 91 \\
\hline & & & \multicolumn{2}{|c|}{ Total de entrevistas (realizado) } & 85 \\
\hline
\end{tabular}

${ }^{1}$ RAS $=$ Conjuntos resultantes da amostragem sistemática; ${ }^{2} \mathrm{UH}=$ Unidades habitacionais resultantes da amostragem sistemática; ${ }^{3} \mathrm{TAC}=$ Tamanho amostral calculado; ${ }^{4} \mathrm{TAA}=$ Tamanho amostral ajustado; ${ }^{5} \mathrm{TAE}=$ Tamanho amostral efetivo; e ${ }^{6} \mathrm{PT}=$ População total.

\section{Resultados e discussão}

Políticas de provisão de habitações como solução para o déficit habitacional e instabilidade residencial

Déficit habitacional e PHIS

Os dados do déficit habitacional para a Região Metropolitana do Recife (RMR), muito além de representarem um quantitativo de moradias a alcançar visando à resolução do problema do acesso, fornecem correlações interessantes no que tange à instabilidade residencial e à desigualdade. Ressalvando que as necessidades habitacionais abrangem especificidades que vão além dos indicadores utilizados na composição do déficit fornecido pela FJP, observa-se pela análise de informações disponíveis no Plano Nacional de HabitaçãoPLANHAB (BRASIL, 2009), o alinhamento da falta de moradias com a desigualdade na distribuição de renda.

Os dados relativos especificamente ao município do Recife não estavam disponíveis para todos os anos, então, como os dados foram observados de forma relacional e em articulação com outros fatores para suporte dos argumentos apresentados, considerou-se que a informação para a RMR como um todo seria significante. Também se levou em conta que Recife, naturalmente, concentra a maior parte dos percentuais relativos ao déficit da sua região metropolitana.

Assim como a distribuição do déficit habitacional da RMR, concentra-se fortemente dentre aquelas famílias com renda mensal de até três salários mínimos (em mais de $80 \%$, tendência igualmente verificada na média das RM do Brasil), de forma correspondente, distribuem-se os grupos por condições de arcar com financiamentos habitacionais em momento anterior (Figura 2). Em 2009, no PLANHAB, observou-se que seriam necessárias 35 milhões de moradias para suprir as necessidades habitacionais do Brasil acumuladas até aquele instante e estimada até 2024. Quando se pondera a distribuição dessas unidades de acordo com os rendimentos e a capacidade de financiamento, nota-se que mais de $80 \%$ encontravam-se nos grupos abaixo das linhas de financiamento $(36,97 \%)$ ou necessitavam de parte do valor do imóvel sob a forma de subsídios governamentais (47\%).

Mas se naquele instante (em 2009) a "solução" para tal quadro, seria a implantação do PMCMV e maiores incentivos à PHIS, torna-se importante avaliar a efetividade dessas políticas em relação à redução desse quadro de desigualdade, para além da redução do déficit. Retornando à Figura 2, ainda é possível verificar que entre 2011 e 2014, na sequência de anos em que essas ações ocorreram com mais intensidade, a situação da distribuição do déficit praticamente não se altera na RMR, indicando um reduzido impacto dessas ações em relação a essa variável.

Distribuição do déficit habitacional na RMR por faixa de renda 


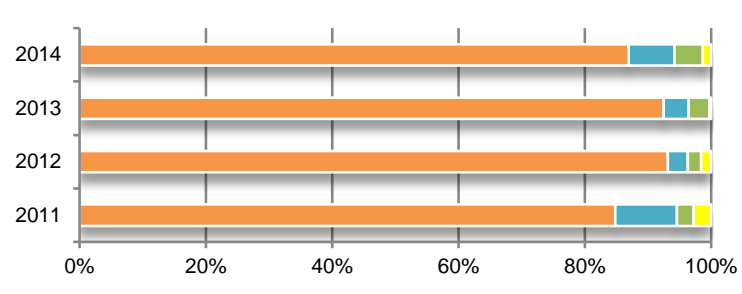

" até 3 s.m. " mais de 3 a 5 s.m. " mais de 5 a 10 s.m. " mais de 10 s.m.

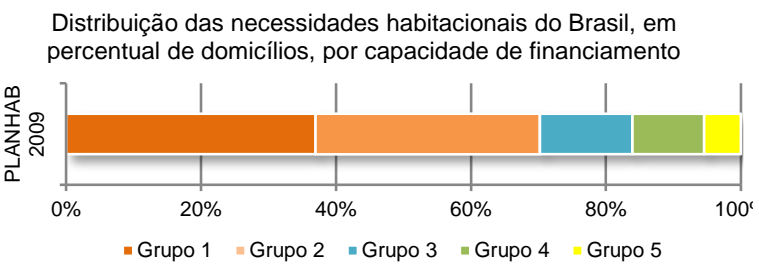

Figura 2. Correlações entre a capacidade para obtenção de financiamentos no Brasil (2009) e distribuição do déficit habitacional por faixa de renda na RMR (20112014). Fonte: IPEA (2009) e FJP (2015, 2016). Nota: Grupo 1 - Famílias com renda líquida abaixo da linha de financiamento; Grupo 2 - Famílias que acessam ao financiamento habitacional, mas que requerem subsídio de complemento e equilíbrio; Grupo 3 - Famílias que podem acessar ao financiamento habitacional, com subsídio de equilíbrio; Grupo 4 - Famílias com capacidade de assumirem financiamento habitacional; e Grupo 5 - Famílias com capacidade de acesso a imóvel por meio de financiamento de mercado.

Os dados em relação aos investimentos na provisão habitacional por parte do poder público revelam que o PMCMV recebeu um volume de recursos bem maior que as ações na PHIS (Nascimento e Bautista, 2016) e que a distribuição dos recursos internamente no PMCMV, apesar de favorecerem famílias com até três salários mínimos, proporcionalmente, em termos da relação entre valor das unidades financiadas, acaba sendo menor que o que foi investido nas Faixas 2 e 3 (Loureiro et al., 2015). Essas faixas respondem por empreendimentos que totalizam uma menor quantidade de unidades habitacionais, porém com maior valor por unidade habitacional e em melhores localizações, considerando os estudos realizados em regiões metropolitanas (Amore et al., 2015; Silva e Tourinho, 2015).

As famílias que recebem até três salários mínimos, correspondem aos beneficiários da Faixa 1 , com renda limite que variou de
$\mathrm{R} \$ 1.395,00$ na Fase 1 do PMCMV, aos $\mathrm{R} \$ 1.800,00$ vigentes na Fase 3. A Faixa 1 é considerada habitação de interesse social por parte de setores da administração pública, mas não é caracterizada ou definida pela participação popular em processos de produção social da moradia, fatores que deveriam ser inseparáveis das ações em Habitação de Interesse Social de fato. Apesar de contemplar famílias de baixa renda em condição de instabilidade residencial, nesta pesquisa distinguimos esses dois tipos de provisão e não foram observados empreendimentos do PMCMV, considerando que nas ações diretas desse programa, ocorre maior influência de interesses do empresariado privado dos setores da construção civil e imobiliário, observando-se ainda, que recursos do FNHIS são direcionados para obras do PAC a fim de congregar interesses privados e da administração pública na gestão territorial.

A partir da análise dos dados do PMCMV até 2012 (BRASIL, 2018), também foi possível identificar a dispersão dos empreendimentos na Faixa 1 do programa para "fora" da capital recifense, onde a maior parte das unidades habitacionais encontra-se nas Faixas 2 e $3(47,08 \%$ e $46,15 \%$, respectivamente, e apenas $6,78 \%$ na Faixa 1). Se considerarmos o somatório dos outros 14 municípios da RMR, são 40,82\% de unidades habitacionais na Faixa 1, 40,59\% na Faixa 2 e $18,60 \%$ na Faixa 3, atestando de uma forma geral que na RMR, a distribuição ocorreu de forma similar à retratada pelos autores mencionados logo acima. Silva (2016) realizou análise mais específica dos empreendimentos da Faixa 1 localizados na RMR, entregues até 2012, e concluiu que o PMCMV provavelmente representou um aumento nas desigualdades socioespaciais.

Para Marques e Frey (2015), os resultados do desenvolvimento desses programas, apesar de serem responsáveis por um inegável desenvolvimento do setor da construção civil e na comparação dos dados dos censos demográficos brasileiros de 2000 e 2010, responderem por um crescimento no total de domicílios maior do que o crescimento da população, não foram significativos para a redução do déficit habitacional, que se encontra estabilizado no país. Se considerarmos os dados do município do Recife e RMR, entre 2010 e 2015 (Figura 3), observa-se que no Recife o déficit total encontra-se em crescimento, com uma média de 455 domicílios por ano, e na RMR, apesar da queda verificada entre 2010 e 2013 , voltou a subir em 2014 e 2015. 
Revista Brasileira de Geografia Física v11, n.02 (2018) 560-584.

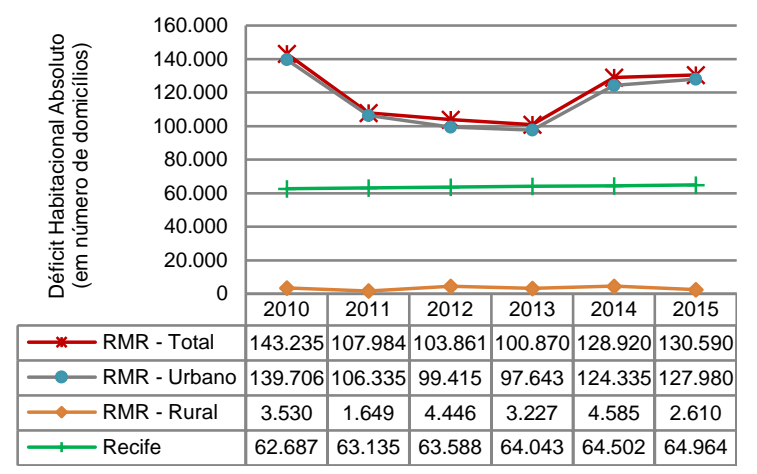

Figura 3. Recife e Região Metropolitana do Recife Déficit habitacional absoluto entre 2010 a 2015. Fonte: FJP (2013, 2015, 2016, 2017).

$\mathrm{Na}$ análise dos componentes do déficit habitacional na RMR entre 2010 e 2015 (os dados para o Recife só estão disponíveis para o ano de 2010), nota-se um comportamento que também se associa à permanência da situação de instabilidade residencial (Figura 4). Trata-se do crescimento do ônus excessivo com aluguel para populações pobres, que na RMR foi de mais de $85 \%$. Zhang e Ball (2016) verificaram que os imóveis para aluguel ainda são predominantemente ocupados pelas populações mais pobres na maior parte do mundo, sendo este um indicador essencial da acessibilidade desigual à moradia.
Em contraposição, verifica-se redução no percentual de domicílios precários, o que pode ser considerado um efeito positivo dos investimentos na habitação de interesse social com total subsídio governamental em obras de urbanização de assentamentos precários, implantação de infraestruturas com realocação de populações ou saneamento integrado, sobretudo, a partir da segunda gestão de Luiz Inácio Lula da Silva. Outros fatores importantes nesse período foram o aumento do poder aquisitivo e o acesso a créditos para compra de materiais de construção, os quais possibilitaram que segmentos da população nas faixas de renda mais baixas, realizassem melhorias em seus imóveis.

Uma última consideração tratou da relação do déficit habitacional com a quantidade de domicílios vagos. Na RMR, nota-se que o estoque de domicílios vagos teve uma diminuição em 2014 em relação ao déficit (Figura 5), mas ainda é praticamente equivalente e no mínimo expressa a contradição entre o estoque de imóveis vagos e o déficit, mesmo que as razões que levam a classificar um domicílio como vago pelo IBGE não sejam precisas, exceto se estão em construção ou reforma, em condição de serem ocupados ou em ruínas.

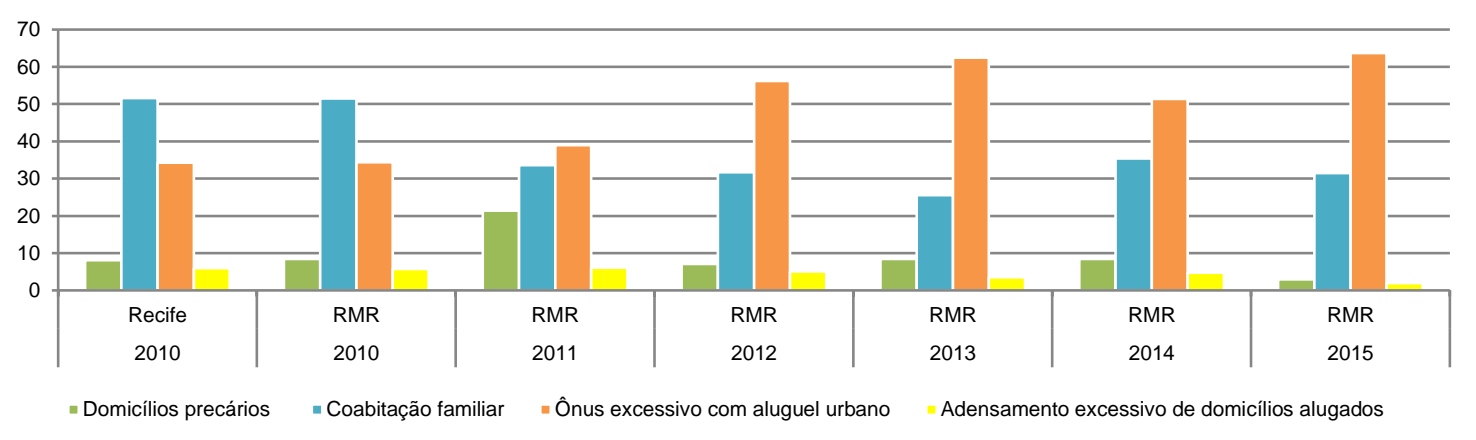

Figura 4. Composição do déficit habitacional (percentual de domicílios em cada grupo) entre 2010 e 2015 na Região Metropolitana do Recife e em 2010, no Recife. Fonte: FJP (2013, 2015, 2016, 2017).

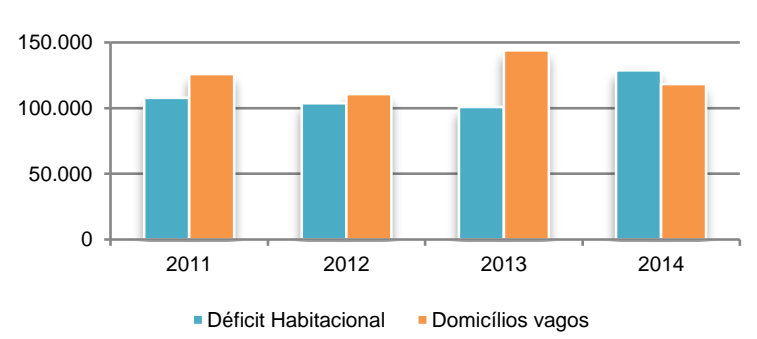

Figura 5. Relação entre a quantidade de domicílios vagos e o déficit habitacional na Região Metropolitana do Recife (2011 a 2014). Fonte: FJP (2015, 2016).

A caracterização do conjunto dos domicílios vagos é considerada de vital importância, pois nesse conjunto possivelmente encontra-se uma parcela significativa de domicílios que poderia ser direcionada a suprir parte das carências habitacionais (FJP, 2016). Estudos também indicam que em alguns municípios do país, a produção em larga escala do PMCMV pode estar contribuindo mais para aumentar o estoque de domicílios vagos (para especulação e aluguel) do que na diminuição efetiva do déficit (Marques e Frey, 2015; Nascimento e Araújo, 2018). Esses dados também demonstram que há muito que avançar no sentido do cumprimento efetivo da função social da propriedade.

Apesar disso, é importante mencionar que estas ações transpuseram barreiras no que concerne ao acesso à moradia, retirando inúmeras pessoas - 
Revista Brasileira de Geografia Física v11, n.02 (2018) 560-584.

em sua maioria, desfavorecidas pelos processos de ocupação desigual do território - de condições muito precárias de habitabilidade. Klintowitz (2016), nesse sentido, aponta as intercorrências na construção e efetivação dos programas habitacionais a partir do Governo de Luiz Inácio Lula da Silva. A autora afirma que as ações e reformulações praticadas consolidaram e originaram novas formas de articulação entre os movimentos de moradia, governos de uma maneira geral e empresários, favorecendo-se pela aura de defesa dos direitos dos excluídos que emergiu com a chegada de Lula ao poder.

Lindert (2016) analisou o desenvolvimento urbano e as mudanças nas políticas habitacionais na América Latina e destacou, para o caso do Brasil, que a evolução democrática no Governo Federal do final do século XX para o XXI, acarretou a descentralização de competências para a escala municipal, reforçando a governança em nível local. Este mesmo autor afirma, ainda, que se trata de lições que o país deu em termos da construção de políticas públicas e que isso gerou novos paradigmas no que tange à provisão de habitações. Considerou, também, impressionantes as experiências de gestão e orçamento participativo em cidades brasileiras, que mesmo não tendo continuidade, implantaram de forma irreversível a consciência de que a população pode fazer parte dos processos decisórios.

Entretanto, coloca a questão da acessibilidade à habitação como um conceito discutido no âmbito internacional na década de 1970, demonstrando que hoje o foco e estratégias já se voltam para outros aspectos como habitabilidade, boa governança, qualidade ambiental, dentre outros (LINDERT, 2016). Observações deste tipo situam o Brasil, assim como os outros países da América Latina, em um contexto anacrônico de discussões, uma vez que aqui a questão da acessibilidade ainda tem muito que avançar.

Mesmo que anacronicamente em relação a outros países, verificando-se os avanços no plano da acessibilidade, abrem-se espaços para discussões de necessidades em outros planos que vão além da aquisição da moradia. Considerando as especificidades dos problemas que vêm sendo elencados na análise do contexto recente - período a partir da implantação de ações em provisão de habitação de interesse social no governo de Luiz Inácio Lula da Silva (2001-2004) e que, mesmo funcionando sob outros moldes sociais, políticos e econômicos, continuam vigentes até o presente momento (2017) - ainda é necessário destacar a importância do combate à falta de acesso à moradia, mas pode-se avançar na busca pela satisfação de novas demandas associadas à equalização dos demais direitos básicos, além de outros requisitos que se aglutinam na alcunha do direito à cidade.

A partir dessas correlações é possível afirmar que os resultados das políticas de habitação de interesse social não tiveram impacto significativo na redução do déficit no Recife e RMR, que segue com um comportamento estável e com tendência a alta no Recife, ainda que eles tenham representado um expressivo volume de novas construções. Como o déficit trata-se de um indicador generalizado, na sequência serão observadas as motivações da implantação das habitações em PHIS, de forma mais específica.

\section{Instabilidade Residencial e PHIS}

Como foi posto na metodologia, essa pesquisa necessitou do aporte do geoprocessamento, sendo boa parte do tempo desprendido na observação de ortofotocartas do município do Recife, ora para descobrir locais mencionados em planilhas fornecidas por órgãos públicos, ora para observação de transformações ambientais. Em alguns momentos, na análise cartográfica, devido à resolução das imagens, surgiram dificuldades de identificação de áreas onde estavam as palafitas ou ocupações precárias, que se confundiam tristemente com amontoados de entulho.

Em princípio, esse grupo faz parte do público alvo das políticas públicas sociais de uma forma geral e das políticas de habitação de interesse social, juntamente com outras pessoas que formam o diverso e amplo cenário das desigualdades e injustiças socioambientais. Nesse tópico, serão discutidas algumas conexões entre a persistência desse tipo de cenário e a efetividade de políticas públicas recentes no setor habitacional.

Considerou-se o termo instabilidade residencial, no sentido recomendado por Desmond e Bell (2015), que propõem um retorno da questão do acesso à habitação regularizada e ambientalmente adequada para a discussão da pobreza, que seria o seu lugar. Para esses autores, as más condições de habitação constituem problema de primeira ordem nos casos de fragmentação e segregação socioespacial, nas injustiças sociais e ambientais; bem como devem ser pensadas mais em função dos "muitos cidadãos não atendidos" pelas ações de provisão do poder público, do que daqueles poucos que já foram.

Dessa forma, uma situação de instabilidade residencial é configurada pela informalidade quanto à posse do imóvel, insegurança quanto à permanência, dependência onerosa do aluguel, desconforto e precariedade da moradia e seu entorno, dificuldades ou nenhum acesso a 


\section{Revista Brasileira de Geografia Física v11, n.02 (2018) 560-584.}

infraestruturas e serviços públicos essenciais. Essas categorias podem ocorrer simultaneamente e obviamente implicam em prejuízos a boas condições de vida nos planos individual, familiar e da coletividade.

Souza (2007, 2010), Souza et al. (2015) e Cavalcanti et al. (2016), no contexto que vem sendo abordado em pesquisas anteriores e que continuam sendo produzidas pelo Observatório de Políticas Públicas de Pernambuco/Observatório das Metrópoles, têm analisado a questão habitacional em Recife no que diz respeito à efetividade das políticas públicas e situação de áreas pobres e/ou assentamentos precários. Esses autores apresentam um amplo panorama de dados oficiais e material cartográfico, a partir de consideráveis esforços de sistematização e análise, que demonstram as dificuldades para diminuição dos espaços de pobreza, para a melhoria das relações de trabalho e geração de renda e quanto ao acesso regularizado à terra, fatores que são traduzidos constantemente na fragmentação socioespacial da cidade.

Nascimento e Bautista (2016) discutiram a situação de insegurança dentre aqueles conjuntos que fazem parte do universo do "interesse social" e apresentam breve análise dos mapas e dados espaciais preliminares do Atlas das Infraestruturas Públicas das Comunidades de Interesse Social (CIS) do Recife (RECIFE, 2016). Reconhecendo a importância estratégica, acadêmica e social do levantamento, podem-se discutir mais algumas questões em função da análise cartográfica realizada sobre a inserção territorial da HIS no Recife, além do evidente crescimento das áreas de interesse social (Figura 6), comparando-se o levantamento atual com levantamentos de áreas pobres realizados em períodos anteriores.

Observou-se que o levantamento das CIS (RECIFE, 2016) é mais específico quanto à homogeneidade interna nos padrões de ocupação dos recortes territoriais, quando se retiram do material apresentado os grandes blocos das Zonas Norte e Sul-Sudoeste (Bairros COHAB, Barro, Ibura e Jordão), ou seja, os morros e seu entorno próximo. Dessa forma, grandes manchas de pobreza da cidade ou de periferias consolidadas, onde inclusive ocorreram muitos investimentos em habitação popular (Melo, 1985; Souza, 1990; Neves, 2006), tiveram suas especificidades locais generalizadas, delimitando CIS de padrões de ocupação internos mais heterogêneos, onde se encontram níveis distintos de precariedade. Nas áreas planas e litorâneas, onde a fragmentação espacial se traduz materialmente em maiores distâncias sociais, nota-se que houve esforço maior em delimitar menores "fragmentos de pobreza", ao nível de ruas ou becos por exemplo.

Essa diferença em termos de generalização/classificação em um primeiro momento pode representar uma tendência de ação em relação às áreas mais bem delimitadas ou consideradas prioritárias. No Atlas (RECIFE, 2016), as CIS são classificadas de acordo com a sua precariedade versus facilidade de intervenção, considerando indicadores de infraestrutura, acesso a serviços e riscos de alagamento e escorregamento (no campo das precariedades) e indicadores relativos à forma de ocupação territorial e regularização fundiária, tais como sua inserção em Zonas Especiais de Interesse Social-ZEIS, ou terrenos de marinha, percentuais de áreas aedificandi e condições de adensamento do solo (no campo das facilidades).

A avaliação do ponto de vista da inserção na dinâmica territorial também foi observada no Atlas para cada CIS como facilidade de intervenção, restringindo-se aos indicadores acima e à observação da "dinâmica imobiliária" no entorno (RECIFE, 2016). Não foi divulgado, no Atlas, o peso dado às variáveis ou de que forma isso implicaria positivamente em facilidades de intervenções nessas áreas ou se a CIS está situada em uma área estratégica do ponto de vista dos interesses do capital empresarial ou bairros "nobres" da cidade. Mas em que isso implica nas PHIS?

Se o levantamento tem o propósito de dar visibilidade às CIS classificando-as em função da precariedade, em termos de gestão, as áreas mais precárias seriam as que apresentam ambientes prioritários para a implementação de políticas sociais. Entretanto, o que se verificou nesta pesquisa é que ao categorizar os ambientes de saída dos moradores dos conjuntos habitacionais construídos em PHIS, as condições precárias de moradia não aparecem como motivação prioritária para remoção, uma vez que a maior parte das realocações ocorreu devido à implantação de projetos de infraestrutura, que envolvem na sua essência a expansão ou melhoria do sistema viário, dando acesso a áreas estratégicas para o capital empresarial/ imobiliário ou que favorecem o transporte individual. 

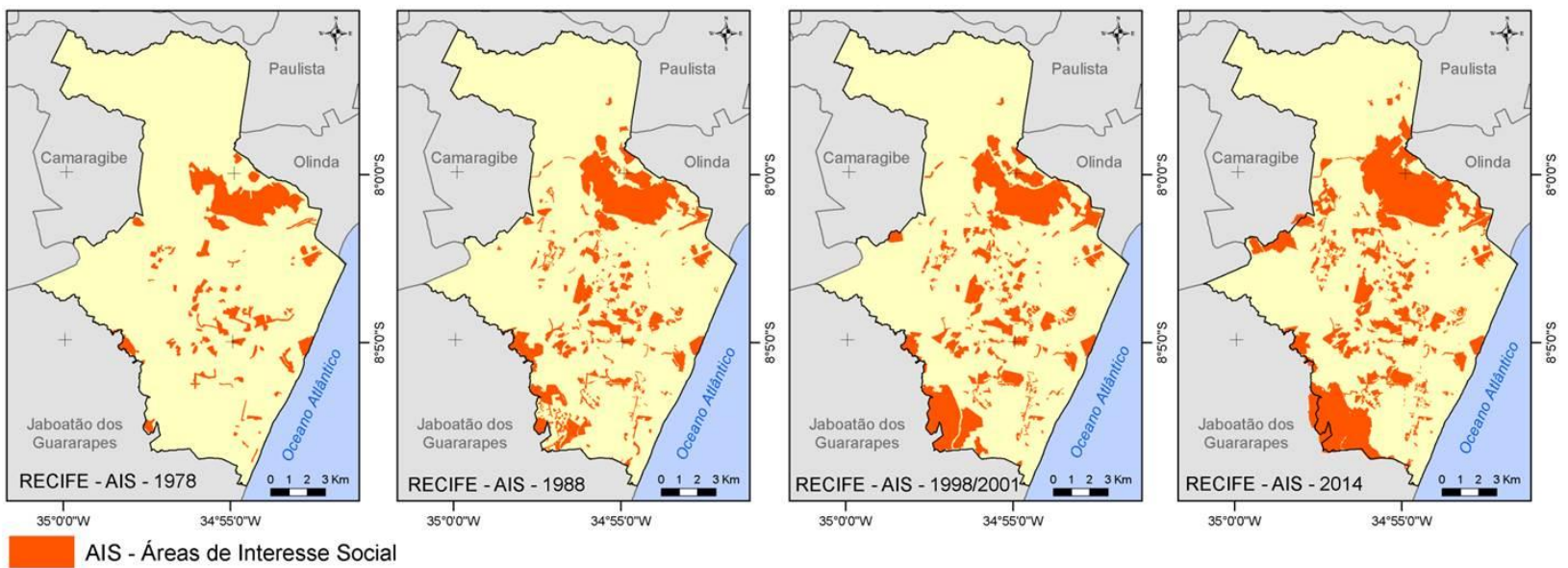

Figura 6. Cadastramentos de áreas de interesse social e fontes das bases cartográficas. Fonte: CONDEPE/FIDEM, SIGAP (2012), RECIFE (2016). Nota: A periodicidade das observações foi condicionada aos anos disponíveis. Os levantamentos foram realizados com metodologias distintas. Em cada levantamento ocorreram denominações diferentes para essas áreas, por isso uniformizamos aqui, para efeitos de comparação, como áreas de interesse social.

Na categorização, as unidades construídas foram divididas em oito tipologias após a análise documental e cartográfica (Figura 7). Inseridas no costumeiro embate entre a falta de planejamento urbano e ambiental e a necessidade de reparação de danos causados por alagamentos ou escorregamentos, $19 \%$ das unidades habitacionais correspondem à demanda emergencial formada pelas famílias que perderam suas moradias em desastres ou encontravam-se na iminência de acidentes por ocuparem áreas de risco.

Um montante de $57 \%$ das unidades construídas envolve a implantação de sistema viário em seus propósitos, sendo que $15 \%$ ocorreram diretamente para esta finalidade, como no caso da implantação da Via Mangue. Nesse caso, observou-se uma desconexão completa da realocação das famílias aos propósitos da HIS, pois a motivação para as intervenções é uma externalidade gerada por articulações entre obras do poder público e os empreendedores do setor privado, marcadas por decisões hegemônicas que visam ao lucro pela apropriação de áreas consideradas estratégicas para as classes hegemônicas locais, como mostram Campos (2015) e Albuquerque e Gomes (2017).

Outro grupo de unidades envolveu a implantação de sistema viário, conectado a ações de urbanização de assentamentos precários situados em áreas estratégicas (18\%). Este grupo é bem exemplificado pelo caso da construção da Av. Beira Rio às margens do Rio Capibaribe, que abriu espaços de verticalização e expansão imobiliária para as classes hegemônicas locais nos bairros Madalena e Torre, valorizados pelas amenidades proporcionadas pela proximidade do rio, antes ocupados pelas palafitas. Seabra et al. (2016) observou que as amenidades naturais no Recife, considerando a presença da praia de Boa Viagem e as margens do Capibaribe, de fato proporcionam a valorização imobiliária, na mesma medida em que a presença de ZEIS ou de áreas de alta criminalidade provocam um efeito contrário.

Dessa forma, nos casos acima, a retirada de palafitas, associada à implantação do sistema viário, constituem mecanismos para atender os interesses preponderantes do setor imobiliário, fator que foi utilizado na classificação das áreas como estratégicas e não estratégicas (periféricas) nesta pesquisa.

Os outros $10 \%$ e $14 \%$ tratam-se da ampliação e melhoria do sistema viário atrelado a grandes obras de saneamento, pelas quais houve a remoção de palafitas e outras tipologias de habitações precárias, só que em áreas periféricas da cidade. Nesse caso, encontram-se principalmente as obras de saneamento e urbanização vinculadas ao PROMETRÓPOLE (Programa de InfraEstrutura em Áreas de Baixa Renda da Região Metropolitana do Recife), nos canais do Arruda e Jacarezinho na Zona Norte do município. Nelas ocorreu a implantação de vias marginais (Sistema Viário 1) e as obras do PAC-Beberibe, achando-se em construção, ainda que a passos lentos, uma avenida às margens do Rio Beberibe que tem o objetivo de conectar a BR-101 ao município de Olinda, nas proximidades do limite com Recife (Sistema Viário 2), dentre outras ações em termos de saneamento e urbanização integrados. 


\section{Revista Brasileira de Geografia Física v11, n.02 (2018) 560-584.}

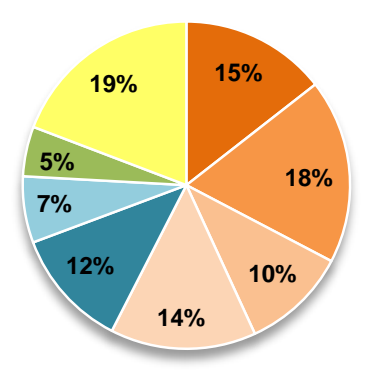
- SISTEMA VIÁRIO EM ÁREA ESTRATÉGICA
- URBANIZAÇÃO DE ASSENTAMENTO PRECÁRIO EM ÁREA ESTRATÉGICA - SISTEMA VIÁRIO
- URBANIZAÇÃO DE ASSENTAMENTO PRECÁRIO - SISTEMA VIÁRIO 1
URBANIZAÇÃO DE ASSENTAMENTO PRECÁRIO - SISTEMA VIÁRIO 2
- URBANIZAÇÃO DE ASSENTAMENTO PRECÁRIO EM ÁREA ESTRATÉGICA
- URBANIZAÇÃO DE ASSENTAMENTO PRECÁRIO
- DEMANDA POR HABITAÇÕES ORIGINÁRIA DE OCUPAÇÕES
DEMANDA EMERGENCIAL POR HABITAÇÕES

\begin{tabular}{|c|c|}
\hline \multicolumn{2}{|l|}{ DETALHAMENTO DOS USOS ATUAIS NOS AMBIENTES DE SAÍDA } \\
\hline Referentes a Conjuntos Habitacionais Concluídos & Nome do(s) Conjunto(s) de Destino \\
\hline \begin{tabular}{l|l} 
Canal do Jacarezinho e Rua da Regeneração \\
\end{tabular} & \multirow{2}{*}{$\begin{array}{l}\text { Saramandaia, Palha do Arroz, Capilé, } \\
\text { Jacarezinho }\end{array}$} \\
\hline Canal do Arruda e Avenida Prof. José dos Anjos & \\
\hline $\begin{array}{l}\text { Margens dos Rios Beberibe e Rio Morno, passando pelos bairros de Peixinhos, Campina do Barreto, Porto da } \\
\text { Madeira e Linha do Tiro e proximidades do rio no bairro Dois Unidos }\end{array}$ & Minerva \\
\hline $\begin{array}{l}\text { Margens do Rio Beberibe, passando pelos bairros de Peixinhos e Campina do Barreto (Lote } 1 \text { do PAC } \\
\text { BEBERIBE) }\end{array}$ & $\begin{array}{l}\text { Beira Rio (H03), Felicidade (H05), Vereador } \\
\text { Miguel Batista (H07), Santo Antônio (H19) }\end{array}$ \\
\hline $\begin{array}{l}\text { Margens dos Rios Beberibe e Rio Morno, passando pelos bairros de Porto da Madeira e Linha do Tiro (Lote } 2 \\
\text { do PAC BEBERIBE) }\end{array}$ & $\begin{array}{l}\text { Portão do Gelo (R02), } 8 \text { habitações no } \\
\text { Minerva (R04), Naná Vasconcelos (R06), } \\
\text { Governador Eduardo Campos (R12), } \\
\text { Beberibe I (R16) e Solano Trindade (R17) }\end{array}$ \\
\hline Policlínica Salomão Kelner & Zeferino Agra \\
\hline Terreno desocupado às margens da Av. Agamenon Magalhães, no cruzamento com a Av. Norte. & Vila Imperial \\
\hline $\begin{array}{l}\text { Parte da ZEIS Campo da Vila - Conjunto habitacional em PHIS e no seu entorno, restante da comunidade não } \\
\text { direcionada para novas habitações }\end{array}$ & Campo da Vila \\
\hline $\begin{array}{l}\text { Parte da ZEIS Vila Esperança-Cabocó em processo de reocupação (houve um deslocamento de apenas } 16 \\
\text { famílias para o } \mathrm{CH} \text { na mesma área) }\end{array}$ & Vila Esperança \\
\hline $\begin{array}{l}\text { Parte urbanizada na ZEIS Mangueira da Torre - Conjunto habitacional em PHIS e no seu entorno, restante da } \\
\text { comunidade não direcionada para novas habitações }\end{array}$ & Mangueira da Torre \\
\hline Conjunto habitacional concluído (mesma área da ocupação) & Dom Hélder Câmara \\
\hline $\begin{array}{l}\text { Margem do Rio Capibaribe com poucos fragmentos de manguezais recompostos e ocupações residenciais } \\
\text { realizadas após remoção (anteriormente Comunidade Abençoada por Deus, predominantemente de palafitas) }\end{array}$ & Abençoada por Deus \\
\hline $\begin{array}{l}\text { Margens do Rio Capibaribe (Av. Beira Rio e trecho de manguezal recomposto) - (anteriormente Arlindo } \\
\text { Dantas, predominantemente de palafitas) }\end{array}$ & \multirow[t]{2}{*}{ Beira Rio da Torre } \\
\hline $\begin{array}{l}\text { Margens do Rio Capibaribe (Av. Beira Rio e trecho de manguezal recomposto) - (anteriormente José de } \\
\text { Holanda, predominantemente de palafitas) }\end{array}$ & \\
\hline $\begin{array}{l}\text { Margens do Rio Capibaribe, com trecho de manguezal recomposto, próximas à Rua Afonso de Albuquerque } \\
\text { Melo e Praça Barão de Caiara (anteriormente Comunidade Vila Vintém II, predominantemente de palafitas) }\end{array}$ & \multirow{2}{*}{ Casarão do Cordeiro } \\
\hline Orla de Brasília Teimosa & \\
\hline Entorno do Campo de Futebol do Bueirão no bairro da Torre & Bueirão \\
\hline $\begin{array}{l}\text { Parte da ZEIS Coelhos - Terreno desocupado à margem do Rio Capibaribe, com presença de fragmentos de } \\
\text { manguezal recomposto, circundado por palafitas que ainda estão no local }\end{array}$ & Travessa do Gusmão \\
\hline Praça com quadra poliesportiva, locais de convivência e parque infantil, via de acesso & Padre Miguel \\
\hline $\begin{array}{l}\text { Habitações em locais dispersos na ZEIS Brasília Teimosa (as famílias que vieram para o conjunto residiam } \\
\text { em palafitas ou diversas ruas da localidade e parte de moradores lutaram pela moradia por cerca de } 16 \text { anos, } \\
\text { inclusive ocupando e dormindo no terreno do habitacional, segundo relato dos moradores) }\end{array}$ & Brasília Teimosa \\
\hline $\begin{array}{l}\text { Conjunto Habitacional e área livre com fragmento de manguezal, onde não foram implantadas todas as } \\
\text { unidades habitacionais propostas (a área foi ocupada na década de } 90 \text { por } 190 \text { famílias, logo desocupada } \\
\text { com a promessa da construção de moradias para as famílias, que em sua maioria eram provenientes do } \\
\text { entorno do Aeroclube - Comunidades do Bode e Encanta Moça) }\end{array}$ & Sitio Salamanta \\
\hline $\begin{array}{l}\text { Via Mangue, 19o Batalhão da Polícia Militar - André Vidal de Negreiros, trecho de margem do Rio Tejipió (foz) } \\
\text { próximo à Ponte Paulo Guerra (anteriormente Beira Rio e Jardim Beira Rio) }\end{array}$ & Via Mangue I \\
\hline Via Mangue (anteriormente Ilha do Destino, Paraíso e Pantanal) & Via Mangue II \\
\hline Via Mangue (anteriormente Deus Nos Acuda e Xuxa) & Via Mangue III \\
\hline $\begin{array}{l}\text { Pátio de estacionamento da Universidade Salgado de Oliveira - UNIVERSO, Rua Sargento Silvio Delmar } \\
\text { Holembach e Estrada do Frigorífico }\end{array}$ & $\begin{array}{l}\text { São Francisco de Assis, Imbiribeira I- } \\
\text { Nicolau Copérnico, Imbiribeira II - Cinco de } \\
\text { Março }\end{array}$ \\
\hline $\begin{array}{l}\text { Parte da ZEIS Aritana - Conjunto habitacional em PHIS e no seu entorno, restante da comunidade não } \\
\text { direcionada para novas habitações }\end{array}$ & 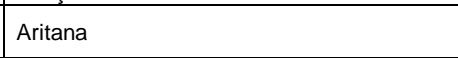 \\
\hline ZEIS Ilha de Deus & $\begin{array}{l}\text { Ilha de Deus II ( } 78 \text { habitações fora da ilha, } \\
\text { entre a Rua Prof. Rosilda Costa e Av. Sul) }\end{array}$ \\
\hline Conjunto habitacional nas proximidades do CAIC & \multirow{2}{*}{ Primeiro de Maio } \\
\hline Encostas de morros na comunidade 27 de novembro & \\
\hline Referentes a conjuntos habitacionais em obras, em ritmo lento de construção ou paralisados & Nome do(s) Conjunto(s) de Destino \\
\hline Margens do Rio Beberibe, passando pelos bairros de Peixinhos e Campina do Barreto (Lote 1 do PAC BEBERIBE) & $\mathrm{H} 08, \mathrm{H} 11, \mathrm{H} 12, \mathrm{H} 13$ \\
\hline $\begin{array}{l}\text { Margens dos Rios Beberibe e Rio Morno, passando pelos bairros de Porto da Madeira e Linha do Tiro (Lote } 2 \text { do } \\
\text { PAC BEBERIBE) }\end{array}$ & Miguel Arraes (R13), R14 \\
\hline $\begin{array}{l}\text { Conjunto habitacional não concluído, e no seu entorno o restante da comunidade não direcionada para novas } \\
\text { habitações }\end{array}$ & Lemos Torres, Casarão do Barbalho \\
\hline Conjunto habitacional não concluído (mesma área da ocupação/comunidade) & Mulheres de Tejucupapo, Pilar \\
\hline $\begin{array}{l}\text { Residências de famílias que aguardam realocação e obras paralisadas da ponte que liga os bairros da Iputinga e } \\
\text { Monteiro }\end{array}$ & Casarão do Barbalho \\
\hline $\begin{array}{l}\text { Comunidade Vila Brasil - áreas semiaterradas e sujeitas à inundações às margens do Rio Capibaribe, ocupada } \\
\text { predominantemente por palafitas }\end{array}$ & Vila Brasil \\
\hline Canal do ABC e habitações precariamente instaladas em suas margens na Comunidade "Escorregou tá dentro" & Escorregou tá dentro \\
\hline $\begin{array}{l}\text { Parte da ZEIS Coelhos - áreas semiaterradas e sujeitas à inundações às margens do Rio Capibaribe, ocupada } \\
\text { predominantemente por palafitas }\end{array}$ & Sérgio Loreto \\
\hline Parte da ZEIS Sítio Grande (CIS Dancing Days) & Sítio Grande - Dancing Days \\
\hline ZEIS Ilha de Deus & Ilha de Deus \\
\hline
\end{tabular}

Figura 7. Categorização das unidades habitacionais construídas em ações de HIS (2001 a 2016), em função das intencionalidades de uso dos ambientes de saída e tipo de intervenções realizadas. Fonte: Pesquisa de dados primários. 


\section{Revista Brasileira de Geografia Física v11, n.02 (2018) 560-584.}

Essas obras mobilizaram grande volume de famílias e envolvem a construção e melhoria de sistema viário de forma secundária, uma vez que primordialmente, são obras de saneamento. Contudo, inserindo as vias construídas e projetadas no contexto da mobilidade entre os municípios de Recife e Olinda, e dado o grande adensamento populacional nessas áreas, não se pode desconsiderar o fator "implantação de sistema viário" na intencionalidade para remover moradias. Ainda é cedo para avaliar a possibilidade de surgimento de áreas de amenidades em trechos da via às margens do Rio Beberibe, principalmente porque as deficiências de infraestrutura e precariedade nos assentamentos humanos são consideravelmente maiores nessa área do que em trechos de maior interesse das margens do Rio Capibaribe, entretanto, é um processo que pode gerar a valorização de certas áreas, ainda que de um ponto de vista bastante localizado.

No momento atual, a referida área situada na zona norte da cidade é a mais dinâmica em termos de produção de moradias em ações de HIS no Recife, configurando programas que, apesar de passarem por problemas de ordem financeira, pelo condicionamento aos repasses do Governo Federal no andamento das obras e da geração de problemas e demandas sociais e ambientais recorrentes na realocação de pessoas, têm respondido por um expressivo volume de retirada de pessoas que se encontravam em condições de habitação extremamente precárias, como mostram Bautista e Castilho (2014) e Nascimento et al. (2017). Observando-se que essas realocações não ocorrem diretamente atreladas ao fator de fomento à exploração capitalista do espaço urbano, como foi mencionado nos dois casos anteriores.

De uma forma geral, tratam-se de áreas bastante adensadas em termos populacionais e de volume de construções. Como visto na Figura 6, elas configuram o grande bloco de CIS com elevada densidade construtiva em áreas de morros, fatores que juntos se traduzem em uma alta demanda por serviços públicos e de infraestrutura, o que é primordial a ser considerado no momento das realocações.

Finalmente, chegamos aos grupos completamente desatrelados da implantação de sistema viário, onde ocorreram ações caracterizadas pela implantação de habitações sob o PHIS, partindo de necessidades priorizadas pela apreciação do poder público (12\% e 7\%) ou quando foram reivindicadas pela população (5\%). A divisão das ações de provisão de moradias em dois grupos, no caso da urbanização de assentamentos precários, também foi realizada em função da situação territorial do ambiente de saída, assim como nos casos anteriores. A partir disso, pôde-se observar que a maioria das unidades habitacionais construídas envolvia ações em comunidades inseridas em áreas propícias à exploração empresarial.

Dentre os casos dessas ações em áreas estratégicas, encontram-se oito conjuntos habitacionais, no âmbito de intencionalidades diversas para remoção das pessoas dos ambientes de saída, os quais têm em comum a localização em áreas centrais da cidade ou na zona sul. Como é o caso das pessoas que residiam em terreno próximo à ZEIS Campo do Vila no bairro Espinheiro, às margens da Av. Gov. Agamenon Magalhães, importante eixo viário na área central do município, e que foram direcionadas para o Conjunto Habitacional Vila Imperial, no bairro Arruda, Zona Norte da Cidade.

$\mathrm{O}$ último grupo corresponde às unidades habitacionais construídas em virtude da ação de movimentos sociais, que de forma geral, ocuparam terrenos que não cumpriam com a função social da propriedade e que, durante longos processos de negociação e resistência, receberam suas casas no mesmo local da ocupação, como no caso do Conjunto Habitacional Dom Hélder Câmara ou em outras áreas, como ocorreu em relação à construção do Conjunto Habitacional Zeferino Agra, resultante de uma ocupação do Movimento dos Trabalhadores Sem Teto (MTST), no pátio da antiga feira do bairro Água Fria. Nesse grupo poderiam ter sido contabilizadas 272 unidades do Conjunto Habitacional Mulheres de Tejucupapo, mas as obras permanecem em estado de paralização ou em ritmo lento desde 2010, permanecendo as famílias na dependência do auxílio-moradia (atualmente no valor de $\mathrm{R} \$ 200,00)$, que se juntam a um grupo de cerca de 6000 famílias no Recife, de acordo com dados da Defesa Civil. Silva (2017) traz detalhes do processo de implantação de habitações nesse contexto, bem como a ação do Movimento de Luta nos Bairros, Vilas e Favelas (MLB) na RMR.

A partir dessas intencionalidades que motivaram as realocações, nota-se que os fatores determinantes para remoções não foram em princípio a condição de precariedade verificada, mas a posição da localidade em relação às intervenções, principalmente aquelas que envolvem a implantação de sistema viário ou modificações nos usos e ocupação de áreas estratégicas. Espera-se que o levantamento das CIS (Recife, 2016) sirva de reforço na priorização de comunidades que estão fora das áreas de interesse das classes hegemônicas. $\mathrm{Na}$ contramão da positividade dessa expectativa, Cavalcanti et al. (2016) mostram que as oportunidades de benefícios 
Revista Brasileira de Geografia Física v11, n.02 (2018) 560-584.

nas políticas habitacionais foram desiguais, mesmo para quem se encontrava há muito tempo em condição precária, no entanto destacam a importância dos avanços institucionais.

Em relação às PHIS, viu-se que esta foi subjugada à realização de grandes projetos de saneamento ou infraestrutura, ao invés de fomentar a emergência de formas mais descentralizadas e consensuais de provisão habitacional, que fossem alternativas à construção de conjuntos habitacionais resultantes do reassentamento involuntário de populações que estavam "no caminho" de obras. Assim, as ações nas PHIS já saem da esfera do planejamento para resolver o problema habitacional de uma forma secundária, como parte da solução para problemas ambientais urbanos resultantes principalmente do acúmulo de deficiências em termos de saneamento e infraestrutura. E como foi visto, em grande parte condicionada por intencionalidades externas às necessidades intrínsecas das populações que foram alvo das realocações.

Reafirmando as críticas ao modelo de provisão de habitações de interesse social que privilegia a realocação de pessoas para conjuntos habitacionais (Nascimento e Bautista, 2016) e que subestima possibilidades do uso de instrumentos como o Estatuto da Cidade ou formas alternativas de produção social da moradia, convém fazer algumas ponderações.

Não se deve desconsiderar a melhoria das condições de vida de muitas famílias por meio das ações em HIS, independentemente das intenções, o que foi verificado em campo, como pode ser observado na Figura 8. No momento em que as pessoas foram questionadas em relação às condições de moradia, apesar de já terem listado muitos problemas, $77 \%$ afirmaram que "mudou para melhor", mesmo que $12 \%$ tenham feito alguma ressalva.

Mas inserindo esse resultado no quadro geral de instabilidade residencial, é importante esclarecer que a questão da intencionalidade emerge não pela negação de benefícios a quem foi contemplado, mas, pela demonstração de que quem está "fora do caminho", mesmo que esteja em condições muito precárias, pode ficar fora desse tipo de intervenção pública. O que, aliás, segue a natureza inerente à lógica do processo do processo de formação territorial no Brasil.

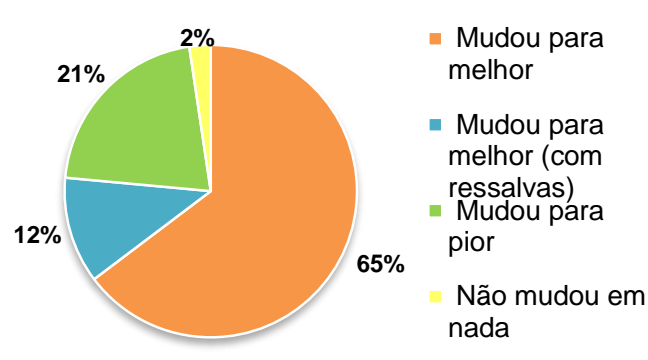

Figura 8. Percepções dos entrevistados em relação à mudança nas condições da moradia. Fonte: Pesquisa de dados primários, 2017. Organização dos autores, 2017.

Indicadores do contexto socioeconômico e padrões de reuso do ambiente urbano

Dividido em seis Regiões PolíticoAdministrativas (RPA) e em 94 bairros, Recife possui uma elevada densidade demográfica, de 7.039,64 hab $/ \mathrm{km}^{2}$ de acordo com os dados do Censo 2010 (IBGE, 2011), que se acentua consideravelmente ao nível dos bairros, chegando a $29.069 \mathrm{hab} / \mathrm{km}^{2}$ no bairro Alto José do Pinho, situado na referida área da Zona Norte que forma um grande bloco de CIS, com bairros fortemente adensados. Sobrepondo a localização de conjuntos habitacionais sobre os ambientes de saídas ao comportamento dessa densidade, vê-se que a localização dos maiores aglomerados de conjuntos habitacionais ocorre em bairros situados nas faixas de mais altas densidades demográficas (Figura 9). Considerando todos os pontos mapeados, vê-se a similaridade na localização de conjuntos habitacionais e ambientes de saída em áreas altamente adensadas, na faixa entre $11.652 \mathrm{e}$ $17.458 \mathrm{hab} / \mathrm{km}^{2}$.

Levando-se em conta o quadro geral de adensamento, não é possível afirmar a partir desse indicador que os conjuntos têm influência na redução de pontos de alto adensamento populacional. Da mesma forma que se verifica a alta densidade nos ambientes de saída, ela continua nos conjuntos, devido à necessidade de verticalização e da alocação de muitas moradias em pequenos terrenos ou de sua situação em terrenos de entorno muito adensado. Por outro lado, esse comportamento é uma evidência de que as populações não estão sendo deslocadas para áreas mais distantes e "menos ocupadas", como foi comum em políticas habitacionais passadas. 
Revista Brasileira de Geografia Física v11, n.02 (2018) 560-584.

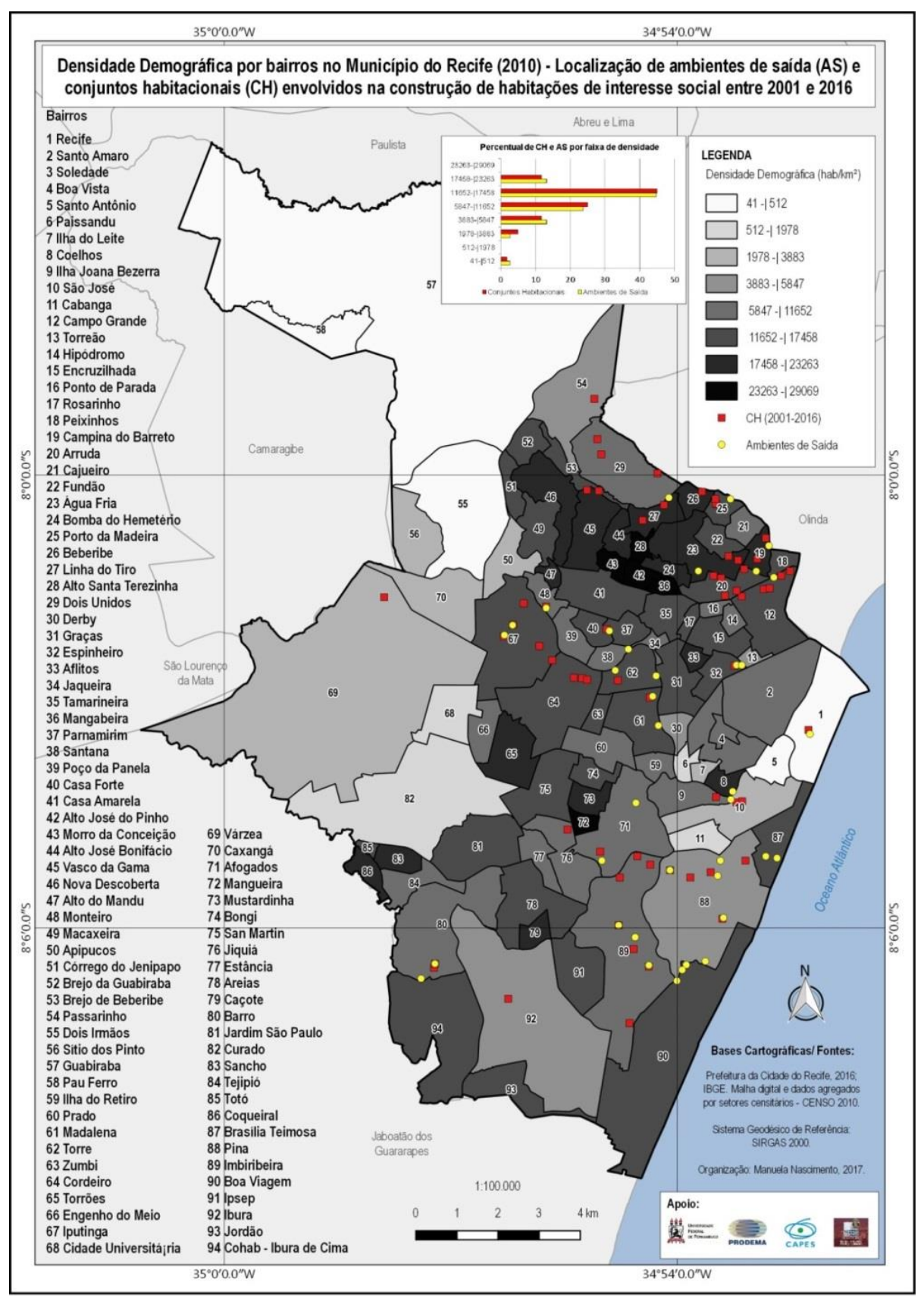

Figura 9. Relações entre a densidade demográfica por bairros no Município do Recife (PE) e localização das áreas pesquisadas. Fonte: Pesquisa de dados primários e secundários.

A elevada densidade demográfica da Zona Norte, onde a população assenta-se em áreas de morros e com baixa infraestrutura, é acompanhada pela condição de estarem nas porções territoriais nas menores faixas de rendimento médio (Figura 10). Esses fragmentos fortemente adensados e de baixos rendimentos espalham-se sobre a cidade, mesclando-se às áreas com altas médias de rendimentos, tais como os blocos que se formam na zona litorânea mais ao sul (principalmente o bairro de Boa Viagem) e na área correspondente aos "doze bairros", que foram estabelecidos como Área de Reestruturação Urbana (ARU) no Plano Diretor da Cidade do Recife em 2008 (RECIFE, 2008), bem como em partes de seu entorno.

Relacionando a localização das faixas de rendimento com a localização de conjuntos habitacionais e ambientes de saída, observam-se terndências mais significativas do direcionamento territorial de populações em função de interesses externos às ações em HIS. Considerando o total de conjuntos (60), tem-se que 55\% dos conjuntos foram alocados em setores nas faixas de renda $1 \mathrm{e}$ 2, que não chegavam a três salários mínimos (mesmo em 2010). Nos ambientes de saída, o percentual é semelhante, diferenciando-se pois ocorreram menos pontos na menor faixa de renda. 
Revista Brasileira de Geografia Física v11, n.02 (2018) 560-584.

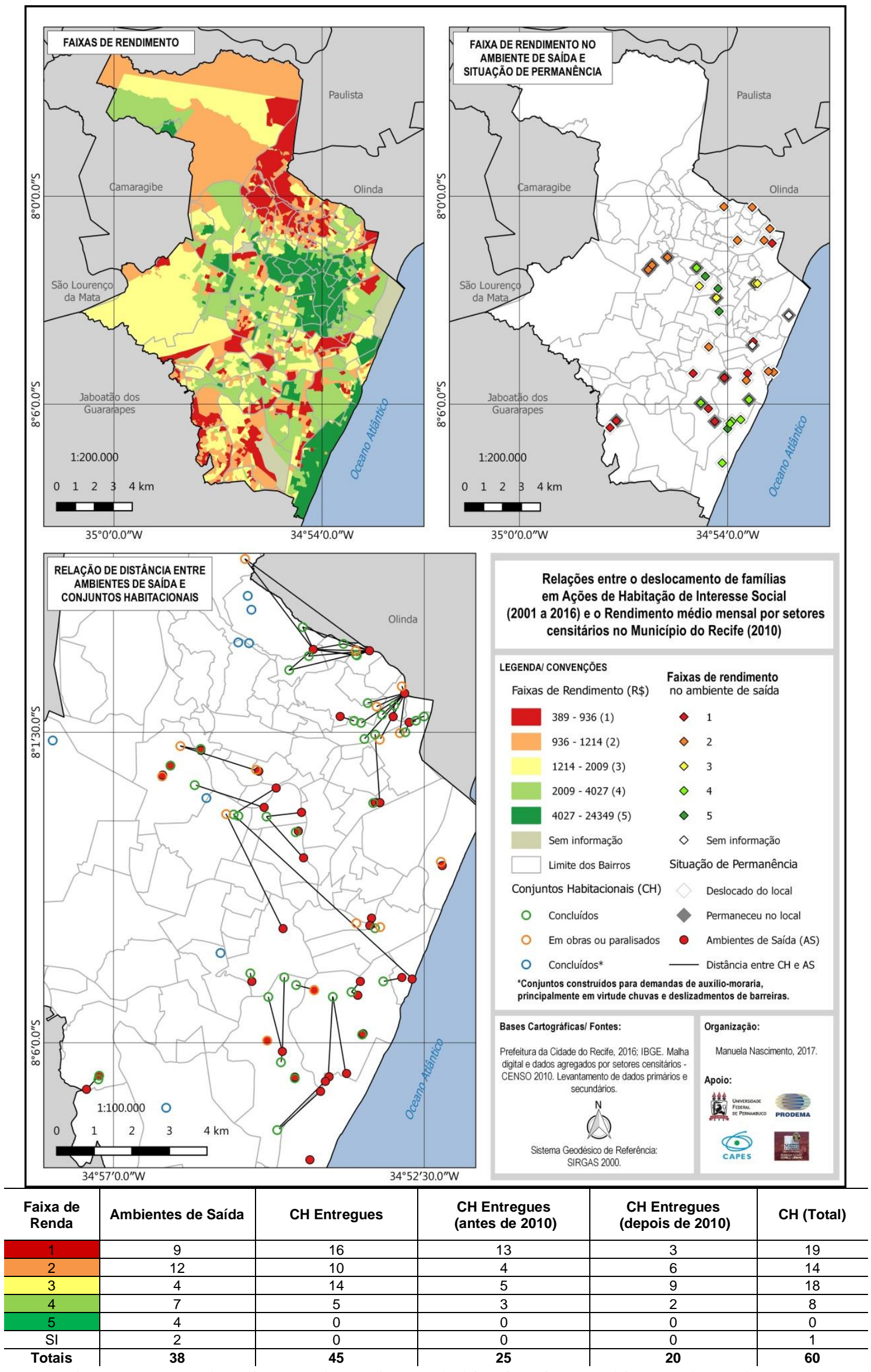

Figura 10. Relações entre a localização de conjuntos habitacionais e ambientes de saída em ações de HIS (2001-2016) e o rendimento médio mensal por setores censitários (2010) no Município do Recife (PE). Fonte: Pesquisa de dados primários e secundários. 
Revista Brasileira de Geografia Física v11, n.02 (2018) 560-584.

Para observação mais específica do indicador, apenas os conjuntos concluídos (45) foram divididos em função do período para o qual o rendimento médio mensal foi calculado, a partir dos dados do IBGE (2011), que tem sua data de referência em agosto de 2010. Dentre esses, 25 já haviam sido contabilizados na data de referência e 20 ainda seriam entregues. Viu-se que setores nas faixas de renda mais baixas representam juntamente os conjuntos habitacionais anteriores a 2010, que formam fragmentos com renda em faixa ainda menor que o seu entorno.

Nesse ponto, é importante distinguir que dentre os 38 ambientes de saída, em 25 houve o deslocamento efetivo da população para outra área e em 13, as pessoas permaneceram no mesmo local ou em proximidades de sua habitação anterior. No caso dos conjuntos oriundos de ocupações, as pessoas eram de outras áreas, mas residiam no mesmo local no momento da intervenção, então, foram colocados no grupo que permaneceu.

Em virtude disso, levando em conta que a maioria dos ambientes de saída representa áreas de deslocamento (25), os "novos conjuntos" até 2010 foram responsáveis pela formação desses fragmentos com concentração de baixas rendas em relação ao entorno. Quanto aos 20 conjuntos não contabilizados, apenas com os resultados da próxima pesquisa censitária, será possível avaliar se a tendência seguirá ocorrendo.

Quanto aos conjuntos situados na faixa 3 (rendimento médio de $\mathrm{R} \$ 1.214,00$ a $\mathrm{R} \$ 2.009,00$ ), notou-se que eles não foram discriminados espacialmente, tendo suas médias de renda associadas ao entorno, o que pode indicar melhoria na referida faixa. Os três conjuntos anteriores a 2010 que estão na faixa 4 correspondem a um conjunto situado no bairro Pina, inserido em setores de maior rendimento, excluindo-se da média os setores da ZEIS Encanta Moça; e a dois pequenos conjuntos alocados nas proximidades da Lagoa do Araçá, também uma área de padrão mais elevado de renda, no bairro Imbiribeira e que tiveram seus rendimentos médios calculados juntamente com as áreas vizinhas.

Em relação aos deslocamentos das pessoas, foi calculada a distância linear entre o ambiente de saída e o conjunto habitacional. Apesar dessa distância ser "fria", pois não representa $o$ deslocamento viário efetivo ou em relação aos vínculos estabelecidos entre uma pessoa e seu lugar de moradia, notou-se que a média das distâncias corresponde a pouco mais de um quilômetro. $\mathrm{Na}$ distribuição dos valores, dentre os 52 conjuntos restantes pela aplicação do segundo critério de

violência, receio da criminalidade infantojuvenil (incluindo o acesso e uso de drogas), bem exclusão, tem-se que 18 conjuntos foram alocados a uma distância linear de menos de 500 metros, nove estão entre 500 metros e um quilômetro, 17 estão entre 1 e 2 quilômetros, seis entre 2 e 4 quilômetros e dois com mais de $4 \mathrm{Km}$ de distância. O maior deslocamento foi verificado no Conjunto Habitacional Casarão do Cordeiro, um dos mais (se não for o maior) controversos casos de realocação de famílias para um ambiente muito diverso do lugar de origem e que por seu impacto negativo, tornou-se uma referência na desacreditação de ações de habitação de interesse social na cidade, como observado por Castilho e Leandro (2012).

A partir dos resultados da percepção das pessoas realocadas e desse quadro onde as distâncias objetivamente não parecem tão elevadas, nota-se claramente como a dimensão "do que está realmente próximo" à moradia é um fator decisivo na satisfação dos entrevistados e isso seria um fator independente da localização anterior ou atual da família. A maioria dos entrevistados levantou pontos em comum que atestam isso, a partir de afirmações, por exemplo, que estavam satisfeitos com a mudança de um local para outro, mas voltavam aos seus locais de origem para ter acesso a serviços de educação e saúde, bem como para atividades de lazer. Dessa maneira, o "perto" ficou "longe" e nos casos em que esses serviços e espaços de lazer estavam próximos, havia maior satisfação.

A questão da distância do local de origem teve um peso maior no caso das pessoas que trabalhavam nas proximidades de suas antigas áreas, pois o custo com o uso do transporte público para o deslocamento do "novo local" ao trabalho tem um peso muito grande no reduzido e inconstante orçamento familiar. Inclusive, os custos com transporte juntam-se às despesas com contas de luz e energia, encontrando-se entre os maiores problemas elencados pela população pesquisada.

Essas evidências demonstraram que o fator de deslocamento para áreas mais distantes não é um indicativo direto de insatisfação na maioria dos casos, como ocorre no caso do Casarão do Cordeiro, onde se verifica uma mudança mais profunda na alteração dos modos de vida da população devido à grande diferenciação (anteriormente à beira-mar). Notou-se que a necessidade de melhorias no acesso a serviços na proximidade do novo local, a dificuldade de acesso ao transporte público, o tamanho da habitação e impossibilidade de ampliação, a passagem para imóveis do tipo apartamento, vivenciar novas situações de

como a adaptação às novas formas de vida comunitária foram fatores mais preponderantes na 
Revista Brasileira de Geografia Física v11, n.02 (2018) 560-584.

insatisfação do que o desejo de permanência ou retorno ao antigo local de moradia.

Dentre esses fatores, a carência nas condições de ocupação e situação de desemprego também esteve dentro das categorias de problemas mais avaliadas negativamente (Figura 11). Diante da pergunta sobre o impacto da mudança nas condições de ocupação, $15 \%$ consideraram que houve uma mudança positiva, $4 \%$ que sim - mas apenas para algumas pessoas. Somando-se quem achou que mudou para pior ou era e continua ruim, tem-se $66 \%$ das opiniões.

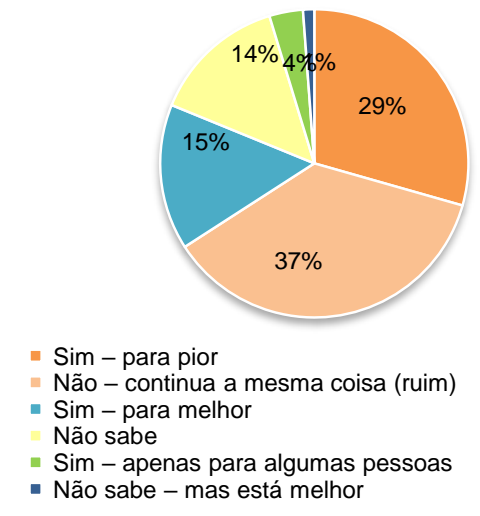

Figura 11. Percepções dos entrevistados em relação às mudanças nas condições de ocupação. Fonte: Pesquisa de dados primários.

De fato, o quadro geral de ocupações das pessoas entrevistadas ou recorrências às ocupações, trata-se de um retrato das dificuldades enfrentadas por muitas pessoas que recebem os menores salários no mercado de trabalho ou vivem na "informalidade", o popular "vive de bico ou biscate", que se traduz em diversas das ocupações listadas (Quadro 2).

No entanto, mesmo levando em conta as respostas dos entrevistados, há de se considerar que a realocação envolve subjetividades que vão muito além do cotidiano ou das práticas de vida. Esse fato deve ser levado em conta pois percebeu-se que grupos em situação de instabilidade residencial tendem a associar seus problemas e insatisfações a necessidades básicas que lhes são privadas para o bem viver. A satisfação quanto à habitação no novo local de moradia ocorre em função de condições anteriores de vida muito vulneráveis e isso não pode ser negligenciado, tanto que a maioria desejava sair do local anterior de moradia, mas ao mesmo tempo, um percentual maior afirmou sentir falta: só que entre as pessoas que alegaram sentir falta $(64 \%), 27 \%$ deixaram claro que havia ressalvas nesse sentimento, pois lá no antigo local a vida era pior (Figura 12).

Esse público alvo da habitação de interesse social, além das determinações ligadas ao crescimento econômico, encontra-se muito suscetível a decisões governamentais, que em sua maioria, são de caráter impositivo e/ou desconectadas da realidade vivida. Pode-se afirmar a partir daí, que importantes variáveis no que tange ao bem viver, são suprimidas em virtude de externalidades desconectadas dos contextos sociais preexistentes. Por exemplo, a articulação das pessoas com seu meio, as práticas sociais e ocupacionais das pessoas relacionadas com sua localização no espaço da cidade, relações identitárias e de vizinhança, bem como o ato de desfrutar de amenidades, tais como a proximidade de rios ou de resquícios do verde urbano, o vento ou a contemplação de paisagens históricas. Tornase fundamental o reconhecimento dessa complexidade do "habitar", para garantir melhores resultados nas intervenções, inclusive na diminuição dos repasses não legalizados ou aluguel dos imóveis, fatos comuns nos conjuntos habitacionais.

En muchas de las ciudades actuales no se puede hablar de que habitamos una ciudad. Más bien, la ciudad nos contiene como si fuera un recipiente donde se colocaran personas y servicios. Habitar la ciudad ocurre cuando vivimos el espacio de forma libre y creativa [...], el arraigo y el encuentro entre los habitantes. Habitar no es «alojarse». No es un asunto de buenas distribuciones de espacios, ni facilitar la vida práctica. No es edificar departamentos con precios asequibles, buena ventilación y asoleamientos, ni pensar de esta manera la vivienda supone una comprensión del habitar (Mansur Garda, 2017, p. 19).

Assim, as políticas efetivamente públicas de habitação - e mais ainda as classificadas como de interesse social - têm que entender, elaborar projetos e implementá-los considerando a complexidade da questão do habitar, o que vai muito além do acesso a uma residência. Então, partindo dos ambientes de saída por desapropriação reivindicada, coercitiva ou alienada da realidade social vivida, as diversas formas de supressão das pessoas dos seus lugares de vida se manifestam na cessão das histórias de vida, na perda dos meios de sobrevivência e nas mudanças radicais do cotidiano, bem como das relações interpessoais e com a natureza. O que extrapola os limites das intervenções e revela que os reusos do ambiente urbano não são favoráveis aos precariamente incluídos. Também ficou claro, que os reusos não indicam transformações ambientais no sentido de recomposição de elementos do sítio natural, fato muito veiculado pela administração pública no 


\section{Revista Brasileira de Geografia Física v11, n.02 (2018) 560-584.}

caso da substituição de áreas degradadas (palafitas) por manguezais.
Isso só foi verificado em três pequenos trechos da margem do Rio Capibaribe, onde a ocupação do entorno pelo capital imobiliário tornou-se muito mais evidente.

Quadro 2. Situação de ocupação dos entrevistados e sua percepção quanto às formas de ocupação no conjunto habitacional

\begin{tabular}{|c|c|c|c|c|c|c|c|}
\hline \multicolumn{8}{|c|}{ Ocupação dos Entrevistados } \\
\hline Dona de Casa & 19 & Ambulante na praia & 2 & Auxiliar de Serviços Gerais & 1 & Funcionária de creche & 1 \\
\hline Desempregado(a) & 13 & $\begin{array}{l}\text { Trabalha em barraca tipo fiteiro } \\
\text { Comerciante na própria }\end{array}$ & 2 & Barraca de Bicho & 1 & Manicure & 1 \\
\hline Aposentado(a) & 11 & residência & 2 & Biscate & 1 & Motoboy & 1 \\
\hline Diarista & 4 & Estudante - Técnico & 2 & Caseiro & 1 & Pensionista & 1 \\
\hline Catador de recicláveis & 3 & Funcionário de Lava-Jato & 2 & Cuidador de idoso & 1 & Líder comunitária & 1 \\
\hline Estudante & 3 & Porteiro & 2 & Vendedora de AVON & 1 & & \\
\hline Ajudante de pedreiro & 2 & Vigilante & 2 & Entregador de água & 1 & & \\
\hline Ambulante & 2 & Cantador de Ciranda & 1 & Estudante universitário & 1 & & \\
\hline \multicolumn{8}{|c|}{ Frequência das ocupações citadas pelos entrevistados como sendo comuns no conjunto habitacional } \\
\hline Doméstica & 17 & Funcionário de mercadinho & 2 & Ambulante & 1 & Trabalha em firma & 1 \\
\hline Diarista & 6 & Estudante & 2 & Eletricista & 1 & Trabalha em telefonia & 1 \\
\hline Desempregado & 5 & Ambulante no centro da cidade & 2 & Recepcionista & 1 & Trabalha no late & 1 \\
\hline Vendedor de água & 5 & Manicure & 2 & Enfermeira & 1 & Trabalha em posto de gasolina & 1 \\
\hline Vigilante/ Vigia & 5 & Vendedor de gás & 2 & Vendedor de cachorro quente & 1 & Trabalha em barraca de bicho & 1 \\
\hline Porteiro & 5 & Conta própria & 2 & Biscate de pedreiro & 1 & Trabalha em bar à noite & 1 \\
\hline Segurança & 4 & Autônomo & 2 & Professora & 1 & Trabalha na construção civil & 1 \\
\hline Zelador & 4 & Trabalha fora & 2 & Servente de pedreiro & 1 & Trabalho informal & 1 \\
\hline Pedreiro & 4 & Trabalha em condomínio & 2 & Lava roupa para fora & 1 & Carteira assinada & 1 \\
\hline $\begin{array}{l}\text { Serviços Gerais } \\
\text { Funcionário do Shopping }\end{array}$ & 3 & Trabalha na praia & 2 & Pensionista & 1 & "Vive de bazar" & 1 \\
\hline Riomar & 3 & Vendedor de fruta e verdura & 1 & Gari & 1 & "Vive do tráfico" & 1 \\
\hline Mecânico & 3 & Trabalha em hospital & 1 & Carrega coisas & 1 & "Faz de tudo" & 1 \\
\hline Aposentado & 3 & Faxineiro & 1 & Comerciante & 1 & $\begin{array}{l}\text { "A gente inventa as coisas" } \\
\text { "Qualquer coisa que dê }\end{array}$ & 1 \\
\hline Trabalha no comércio & 3 & Vendedor de comida & 1 & Agente comunitário de saúde & 1 & dinheiro" & 1 \\
\hline \multirow[t]{2}{*}{ Trabalha em barracas } & 3 & Costureira & 1 & Trabalha em restaurante & 1 & Não sabe & 12 \\
\hline & & Operário & 1 & Trabalha em madeireira & 1 & & \\
\hline
\end{tabular}

Fonte: Pesquisa de dados primários.

(a) desejava sair do antigo local de moradia

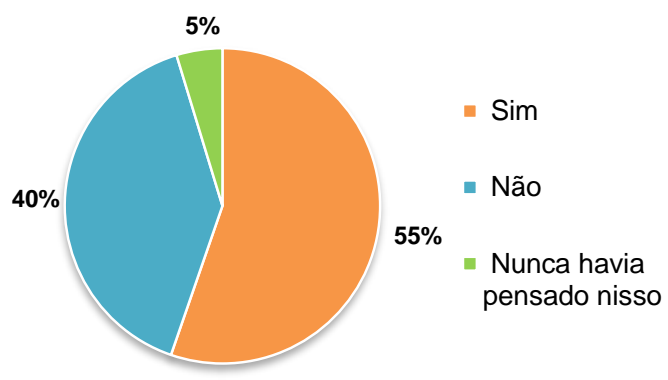

(b) sente falta do antigo local de moradia

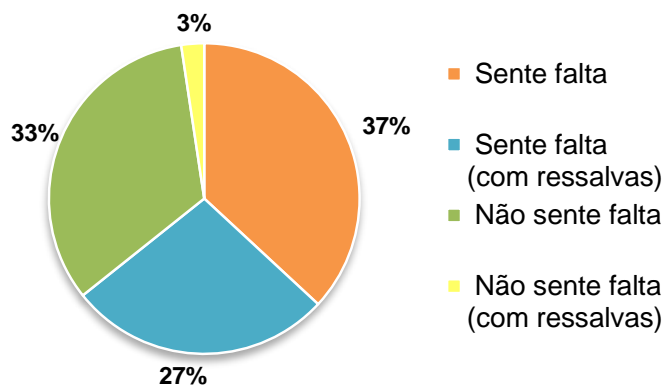

Figura 12. Percepções dos entrevistados em relação à mudança do local de moradia. Fonte: Pesquisa de dados primários.

Acredita-se que uma maior sensibilidade em relação aos fatores da subjetividade, junto à consideração da preponderância de recorrências à falta de satisfação de necessidades básicas específicas, as quais independem do local da moradia, pode representar um avanço em termos da avaliação das políticas públicas, atribuindo-se menos importância ao fato de que a distância do local de origem pode ser um indicativo de fracasso. Os resultados vão ao encontro de indicativos discutidos em 2016 na Terceira Conferência das Nações Unidas sobre Moradia e Desenvolvimento 
Urbano Sustentável - Habitat III (ONU-Habitat, 2016), onde se reafirmou a urgência de mudança de paradigma no modo de planejar, financiar, desenvolver e governar os assentamentos humanos a fim de que ninguém seja deixado para trás, eliminando-se todas as formas e dimensões da pobreza.

\section{Considerações finais}

As justificativas para as transferências têm apresentado diversos tipos de argumentos pautados na recuperação ambiental de áreas da cidade e na melhoria dos assentamentos precários. Entretanto, diante do contexto observado, há nitidamente dois fatores preponderantes: a demanda por espaços para especulação imobiliária e implantação de novos empreendimentos destinados às classes hegemônicas locais e suas atividades, sobretudo no setor de serviços; a sustentação de um imperativo de mobilidade que estes espaços exigem para realizar suas funções e também para o "surgimento" de terrenos valorizados, onde apenas a construção de vias por si só, é utilizada como justificativa para a retirada de pessoas. A mobilidade propiciada com obviedade não se refere àquela necessária e inclusiva da maioria dos habitantes da cidade.

Emergem aí as dissidências éticas dos diversos atores envolvidos na provisão de moradias, principalmente em se tratando das ações do setor público e empreendedores do setor privado, responsáveis por grandes intervenções. Para a efetivação de tais interesses, distantes da realidade das pessoas que habitam tais espaços, utilizam-se do uso do poder e da força, além do senso de oportunidade e conveniência diante das deficiências na legalização da posse da terra nessas áreas. Trata-se, assim, de uma provisão profundamente desigual da habitação para as classes subalternas, que também repercute na problemática ambiental.

Tais perspectivas demonstram, por diferentes vias de interpretação, uma associação entre a formação espacial do meio urbano, danos ao ambiente, necessidade de ajustes nas políticas públicas, processos de fragmentação socioespacial e a importância de dar visibilidade às pessoas e áreas que são postas em condição de constante vulnerabilidade em relação a seus locais de moradia.

No tocante a intervenções públicas que envolvem a realocação de pessoas de suas habitações, pode-se afirmar que a emergência dos problemas supera a aplicação de soluções. Observou-se um quadro onde, por mais precária que fosse a habitação de origem das pessoas, ali já existiam vínculos psicológicos, sociais e econômicos, bem como de adaptação (e até formas diversas de resiliência) às condições de prestação de serviços e à infraestrutura disponíveis, que têm de ser completamente refeitos no local de realocação, no qual obviamente, apenas a ação pontual de construção da moradia, não tem servido de base para essas reconstruções, demonstrando mais uma vez a necessidade de conexão entre as políticas públicas (entre si) e com as necessidades e experiências vividas das pessoas atingidas por suas ações.

\section{Agradecimentos}

Ao Programa de Pós-Graduação em Desenvolvimento e Meio Ambiente (PRODEMA) da Universidade Federal de Pernambuco pelo apoio institucional. À Coordenação de Aperfeiçoamento de Pessoal de Nível Superior - Capes, pela bolsa de Doutorado concedida.

\section{Referências}

Albuquerque, M.Z.A., Gomes, E.T.A., 2017. O jogo do poder na produção do espaço do Recife. Revista Rural \& Urbano 2, 39-56.

Amore, C.S., Shimbo, L.Z., Rufino, M.B.C. (Orgs.), 2015. Minha casa... e a cidade? Avaliação do Programa Minha Casa Minha Vida em seis estados Brasileiros. Letra Capital, Rio de Janeiro.

Balbim, R., Krause, C., Lima Neto, V.C., 2015. Para além do Minha Casa Minha Vida: uma política de habitação de interesse social? Texto para discussão / Instituto de Pesquisa Econômica Aplicada [Online]. Disponível: http://www.ipea.gov.br/portal/index.php?optio $\mathrm{n}=\mathrm{com} \_$content $\&$ view $=$ article\&id=26017. Acesso: 28 set. 2017.

Bautista, D.C.G., Castilho, C.J.M., 2014. Prometropole: política pública de promoción de vivienda digna para poblaciones ribereñas - un desafío al desarrollo humano. Revista Brasileira de Geografia Física 7, 1215-1228.

Bolfarine, H., Bussab, W.O., 2005. Elementos de Amostragem. ABE - Projeto Fisher. Blucher, São Paulo.

BRASIL, Governo Federal, Portal de Dados Abertos, 2018. Empreendimentos do Programa Minha Casa, Minha Vida. Data de referência março/2012. Disponível: http://dados.gov.br/dataset/mpog_mcmv. Acesso: 10 jan. 2018. 
BRASIL, Ministério das Cidades/ Secretaria Nacional de Habitação, 2009. Plano Nacional de Habitação. Disponível: http://www.cidades.gov.br/images/stories/Arqu ivosSNH/ArquivosPDF/Publicacoes/Publiicaca o_PlanHab_Capa.pdf. Acesso: 20 set. 2015.

Bueno, L.M.M., 2008. Reflexões sobre o futuro da sustentabilidade urbana com base em um enfoque socioambiental. Cadernos Metrópole, 19, 99-121.

Campos, D.J.S.L., 2015. A Via Mangue sob o olhar do ordenamento territorial urbano em RecifePE: o lugar dado às famílias pobres. Revista Movimentos Sociais e Dinâmicas Espaciais 4, 207-231.

Cardoso, A.L. (Org.), 2013. O programa Minha Casa Minha Vida e seus efeitos territoriais. Letra Capital, Rio de Janeiro. Disponível: http://www.observatoriodasmetropoles.net/ima ges/abook_file/mcmv_adauto2013.pdf.

Acesso: 14 mai. 2014.

Cardoso, A.L., Aragão, T.A., 2013. Do fim do $\mathrm{BNH}$ ao programa minha casa minha vida, in: Cardoso, A.L. (Org.), O programa Minha Casa Minha Vida e seus efeitos territoriais. Letra Capital, Rio de Janeiro, pp. 17-654.

Cardoso, A.L., Aragão, T.A., Jaenisch, S.T. (Orgs.), 2017. Vinte e Dois Anos de Política Habitacional no Brasil: da euforia à crise. Observatório das Metrópoles, Letra Capital, Rio de Janeiro.

Castilho, C.J.M., Leandro, P.R.F., 2012. Políticas públicas e (re)produção sustentável do espaço urbano: "Programa Recife Sem Palafitas" seus benefícios e sua natureza social. Acta Geográfica 6, 33-58.

Cavalcanti, H., Souza, M.A.deA., Miranda, L., Neves, N., 2016. Tipologia e caracterização dos assentamentos precários: Região Metropolitana do Recife (RMR), in: Morais, M.daP., Krause, C., Neto, V.C.L. (Orgs.), Caracterização e Tipologia de Assentamentos Precários: estudos de caso brasileiros. IPEA, Brasília, pp. 307-376.

Desmond, M., Bell, M., 2015. Housing, Poverty, and the Law. Annual Review of Law and Social Science 11, 15-35.

FJP. Fundação João Pinheiro, 2017. Diretoria de Estatística e Informações. Déficit habitacional no Brasil 2015: resultados preliminares. Disponível:

http://www.fjp.mg.gov.br/index.php/docman/c ei/723-estatisticas-informacoes-3-deficithabitacional-16-08-2017versao-site/file. Acesso: 4 jan. 2018.

FJP. Fundação João Pinheiro, 2016. Centro de Estatística e Informações. Déficit habitacional no Brasil 2013-2014. Disponível: http://www.fjp.mg.gov.br/index.php/docman/c ei/informativos-cei-eventuais/634-deficithabitacional-06-09-2016/file. Acesso: 15 jun. 2017.

FJP. Fundação João Pinheiro, 2015. Centro de Estatística e Informações. Déficit habitacional no Brasil 2011-2012. Disponível: http://www.fjp.mg.gov.br/index.php/docman/c ei/559-deficit-habitacional-2011-2012/file.

Acesso: 15 jun. 2017.

FJP. Fundação João Pinheiro, 2013. Centro de Estatística e Informações. Déficit habitacional no Brasil 2010. Disponível: http://www.fjp.mg.gov.br/index.php/docman/c ei/deficit-habitacional/216-deficit-habitacionalmunicipal-no-brasil-2010/file. Acesso: 15 jun. 2017.

Geneletti, D., La Rosa, D., Spyra, M., Cortinovis, C., 2017. A review of approaches and challenges for sustainable planning in urban peripheries. Landscape and Urban Planning 165, 231-243.

Höfling, E.M., 2001. Estado e políticas (públicas) sociais. Cadernos Cedes 21, 30-41.

IBGE. Instituto Brasileiro de Geografia e Estatística, 2011. Censo demográfico 2010. Agregado por Setor Censitário. IBGE, Rio de Janeiro.

IPEA. Instituto de Pesquisa Econômica Aplicada, 2009. Brasil em desenvolvimento: Estado, planejamento e políticas públicas (Brasil: o estado de uma nação), v. 2. IPEA, Brasília.

Krause, C., Balbim, R., Lima Neto, V.C., 2013. Minha Casa Minha Vida, nosso crescimento: onde fica a política habitacional? Texto para discussão / Instituto de Pesquisa Econômica Aplicada [Online]. Disponível: http://www.ipea.gov.br/portal/images/stories/P DFs/TDs/td_1853.pdf. Acesso: 28 nov. 2015.

Lima, P.G., Fedozzi, L.J., Corrêa, G.C.P., 2016. Participação social e habitação popular: paradoxos e dilemas da participação institucionalizada, in: Marx, V., Costa, M.A. (Orgs.), Participação, Conflitos e Intervenções Urbanas: contribuições ao habitat III. Editora da UFRGS/CEGOV, Porto Alegre. Disponível: http://repositorio.ipea.gov.br/handle/11058/729 6. Acesso: 16 out. 2017.

Lindert, P.V., 2016. Rethinking urban development in Latin America: a review of changing paradigms and policies. Habitat International [Online] 54.5 Disponível: http://dx.doi.org/10.1016/j.habitatint.2015.11.0 17. Acesso: 8 ago. 2016. 
Loureiro, M. R., Macário, V., Guerra, P. H., 2015. Legitimidade e efetividade em arranjos institucionais de políticas públicas: o Programa Minha Casa Minha Vida. Revista de Administração Pública 49, 1531-1554.

Marques, C., Frey, H., 2015. As mudanças habitacionais em regiões metropolitanas brasileiras. URBE, Revista Brasileira de Gestão Urbana 7, 250-267.

Mansur Garda, J.C., 2017. Habitar la ciudad. Revista de Filosofía Open Insight 8, 9-24.

Matos, R., 2008. Grandes territorialidades, planejamento e questões ambientais no Brasil. Cadernos do LESTE, Edição Especial (20002008) 386-401.

Monteiro, J.C.C.S., 2015. Habitação de interesse social em cenários de revalorização urbana: considerações a partir da experiência carioca. Cadernos Metrópole 17, 441-459.

Monteiro, A.R., Veras, A.T.R., 2017. A questão habitacional no Brasil. Mercator (Fortaleza) [Online] $16 . \quad$ Disponível: https://dx.doi.org/10.4215/rm2017.e16015. Acesso: 20 nov. 2017.

Moran, E.F., 2011. Meio ambiente e ciências sociais: interações homem-ambiente e sustentabilidade. SENAC, São Paulo.

Moreira, T.A., Ribeiro, J.A.Z.M.T., 2016. A questão fundiária brasileira no desenho das políticas nacionais de habitação: considerações a partir do início do século XXI. Cadernos Metrópole 18, 15-32.

Nascimento, D.M., 2016. As políticas habitacionais e as ocupações urbanas: dissenso na cidade. Cadernos Metrópole 18, 145-164.

Nascimento, M.M.P., 2017. Relações sociedade e natureza, padrões de cientificidade e perspectivas possíveis para estudos ambientais. Revista Movimentos Sociais e Dinâmicas Espaciais 6, 212-234.

Nascimento, M.M.P., Bautista, D.C.G., 2016. Dinâmica da habitação popular e do "interesse social" no Recife: da Liga Social contra o Mocambo à inflexível passagem para os conjuntos habitacionais. Revista Movimentos Sociais e Dinâmicas Espaciais 5, 185-210.

Nascimento, M.M.P., Bautista, D.C.G., Cavalcanti, R.L.S., 2017. Distribuição espacial e acesso a serviços públicos essenciais em políticas de habitação de interesse social. Revista de Políticas Públicas 21, 225-244.

Nascimento, M.M.P., Araújo, H.M., 2018. A urbanização extensiva de Aracaju e a formação de novos aglomerados habitacionais: avaliação a partir da desagregação de dados dos
CENSOS/ IBGE. Caderno de Geografia PUCMinas 28, 166-196.

Oliveira, R., Sampaio, S.S., Souza, A.J.M., 2017. População de rua e direito à moradia: uma análise a partir do Programa Minha Casa Minha Vida. Sociedade em Debate 23, 225-244.

ONU-Habitat. Organização das Nações Unidas, 2016. Nova Agenda Urbana - Declaração de Quito: Cidades Sustentáveis e Assentamentos Urbanos para Todos. Disponível: http://habitat3.org/the-new-urban-agenda.

Acesso: 20 nov. 2017.

Otalvaro-Sierra, C.A., 2017. Racionalidad estatal y lógica social: la configuración del hábitat. Bitácora Urbano Territorial 27, 57-64.

Prado, R.M., 2012. Viagem pelo conceito de populações tradicionais, com aspas, in: Steil, C.A., Carvalho, I.C.deM. (Orgs.), Cultura, Percepção e Ambiente: diálogo com Tim Ingold. Terceiro Nome, São Paulo.

Proni, M.W., Faustino, R B., 2016. Avanços e limites da política de desenvolvimento urbano no Brasil (2001-2014). Planejamento e Políticas Públicas 46, 181-215.

RECIFE, 2008. Lei $\mathrm{n}^{0} 17.511$, de 29 de dezembro.

RECIFE. Prefeitura do Recife, 2016. Atlas das infraestruturas públicas das comunidades de interesse social do Recife. Recife. Disponível em:

http://mundosafari.com.br/projetos/2015/prefei tura-atlas/. Acesso: 8 out. 2016.

Rodrigues, L.P.D, Moreira, V.S., 2017. Habitação e políticas públicas: o que se tem pesquisado a respeito? Revista Brasileira de Gestão Urbana 8, 167-180.

Rolnik, R., Cymbalista, R., Nakano, K., 2011. Solo urbano e habitação de interesse social: a questão fundiária na política habitacional e urbana do país. Revista de Direito da ADVOCEF 13, 123158.

Seabra, D., Silveira Neto, R., Menezes, T., 2016. Amenidades urbanas e valor das residências: uma análise empírica para a cidade do Recife. Economia Aplicada 20, 143-169.

Souza, M.A., 2009. Pensando a política nacional de habitação para adversidade das famílias e dos municípios brasileiros, in: Bitoun, J., Miranda, L. Desenvolvimento e Cidades no Brasil. Contribuições para o debate sobre as políticas territoriais. FASE: Observatório das Metrópoles, Recife, pp 117-150.

Souza, M.A., 2007. Política Habitacional para os excluídos: o caso da Região Metropolitana do Recife, in: Cardoso, A.L. (Org.), Habitação Social nas Metrópoles Brasileiras. Uma avaliação das políticas habitacionais em Belém, 
Belo Horizonte, Porto Alegre, Recife, Rio de Janeiro e São Paulo no final do século XX. ANTAC, Porto Alegre, pp. 114-149.

Souza, M.A.deA., Lima, R.M.C., Anjos, K.L.dos, Barbosa, A., 2015. As formas de provisão da moradia na configuração socioespacial da Região Metropolitana do Recife, in: Souza, M.A.deA., Bitoun, J. (Orgs.), Metrópoles: território, coesão social e governança democrática. Recife: Transformações na Ordem Urbana. Observatório das Metrópoles, Rio de Janeiro, pp. 241-285.

Silva, A.E., 2016. A produção do espaço urbano pelo programa Minha Casa Minha Vida (faixa
1) na Região Metropolitana de Recife-PE. Dissertação (Mestrado). Recife, UFPE.

Silva, C.F., 2017. Estratégias, conquistas e permanências do MLB nos núcleos da RMR: mecanismos de transformação ou de intermediação com o Estado? Revista Movimentos Sociais e Dinâmicas Espaciais 6, 39-56.

Silva, M.L., Tourinho, H.L.Z., 2015. O Banco Nacional de Habitação e o Programa Minha Casa Minha Vida: duas políticas habitacionais e uma mesma lógica locacional. Cadernos Metrópole 17, 401-417.

Zhang, X.Q., 2016. The trends, promises and challenges of urbanization in the world. Habitat International 54, 241-252. 